\title{
Active and Passive Membrane Properties and Intrinsic Kinetics Shape Synaptic Inhibition in Hippocampal CA1 Pyramidal Neurons
}

\author{
Jason B. Hardie and Robert A. Pearce \\ Department of Anesthesiology, University of Wisconsin, Madison, Wisconsin 53706
}

The impact of synaptic inhibition depends on the passive and active properties of the neuronal membrane as well as on the characteristics of the underlying synaptic conductances. Here, we evaluated the contributions of these different factors to the IPSPs produced by two kinetically and anatomically distinct inhibitory synapses onto hippocampal CA1 pyramidal neurons: somatic $\mathrm{GABA}_{\mathrm{A}, \text { fast }}$ and dendritic $\mathrm{GABA}_{\mathrm{A} \text {,slow. }}$ Using combined current-clamp and voltage-clamp recordings from neurons in hippocampal brain slices, we found that despite pronounced differences in kinetics and only weak voltage dependence of the underlying synaptic conductances, there were much smaller differences in duration but strong voltage dependence of IPSPs arising from somatic and dendritic synapses. Pharmacologic tests and compartmental modeling showed that these effects were produced by the hyperpolarization-activated cation current, $I_{\mathrm{H}}$, which accelerated IPSP decay over a broad range of membrane potentials and reduced IPSP amplitudes at hyperpolarized potentials, and the persistent sodium current, $I_{\mathrm{NaP}}$, which prolonged and amplified IPSPs at depolarized subthreshold potentials. The relative magnitudes of their influences depended on the kinetics of the underlying synaptic conductances: the effect on duration was greater for $\mathrm{GABA}_{\mathrm{A}, \text { fast }}$ and on amplitude was greater for $\mathrm{GABA}_{\mathrm{A}, \mathrm{slow}}$. Passive and active factors thus influence the impact of synaptic inhibition in a location- and voltage-dependent manner.

Key words: $\mathrm{GABA}_{\mathrm{A}}$ receptor; dendrite; IPSP; hyperpolarization-activated cation current; persistent sodium current; compartmental modeling

\section{Introduction}

Studies of synaptic integration in cortical neurons have focused primarily on EPSPs and on how they are shaped by active membrane processes (Lipowsky et al., 1996; Magee, 1999; Hausser et al., 2000). However, inhibitory synaptic transmission also exerts a powerful influence on integrative function. In hippocampal neurons, inhibition regulates excitability in a location-specific manner (Miles et al., 1996; Tsubokawa and Ross, 1996; Tamas et al., 2004; Somogyi and Klausberger, 2005), participates in the generation of theta and gamma oscillations (Soltesz and Deschenes, 1993; Ylinen et al., 1995; Penttonen et al., 1998; Klausberger et al., 2003), and modulates excitatory synaptic plasticity (Davies and Collingridge, 1996; Evans and Viola-McCabe, 1996). Although its importance is recognized, comparatively litthe is known about the factors that shape IPSPs.

Voltage-clamp studies of inhibition in CA1 pyramidal neurons have shown that synapses located at the soma versus dendrites produce kinetically distinct responses, termed $\mathrm{GABA}_{\mathrm{A}, \text { fast }}$

\footnotetext{
Received Feb. 6, 2006; revised July 16, 2006; accepted July 17, 2006.

We thank Dr. Mathew Jones (University of Wisconsin, Madison) for allowing use of laboratory equipment for some experiments, Dr. Frostl (CIBA-Geigy) for the kind gift of CGP55845A, Dr. Ted Carnevale (Yale University) for providing a neuron tool to integrate current in all cellular compartments, Dr. Nelson Spruston for helpful discussions and suggestions, and Mark Perkins for excellent technical support.

Correspondence should be addressed to Robert A. Pearce at the above address. E-mail: rapearce@wisc.edu. DOI:10.1523/JNEUROSCI.0547-06.2006

Copyright $\odot 2006$ Society for Neuroscience $\quad$ 0270-6474/06/268559-11\$15.00/0
}

and $\mathrm{GABA}_{\mathrm{A}, \mathrm{slow}}$ (Pearce, 1993; Banks et al., 1998). Their anatomical and kinetic properties may allow these synapses to serve different functional roles. For example, fast somatic inhibition $\left(\tau_{\text {decay }} \sim 7 \mathrm{~ms}\right)$ is well suited to control action potential generation (Cobb et al., 1995) and facilitate coincidence detection (Pouille and Scanziani, 2001), whereas slow dendritic inhibition $\left(\tau_{\text {decay }} \sim 50 \mathrm{~ms}\right)$ may regulate dendritic electrogenesis, action potential backpropagation, and NMDA receptor activation (Miles et al., 1996; Tsubokawa and Ross, 1996; Kapur et al., 1997).

The physiological impact of these inhibitory synapses may also depend on other active and passive membrane properties. Two particularly relevant active currents in this regard are the hyperpolarization-activated cation current, $I_{\mathrm{H}}$, and the persistent sodium current, $I_{\mathrm{NaP}}$ (French et al., 1990; Magee, 1998). Both display strong voltage dependence within the appropriate voltage range (Crill, 1996; Pape, 1996). $I_{\mathrm{H}}$ is a mixed cation current that in CA1 pyramidal cells is essentially inactive at $-57 \mathrm{mV}$ but becomes activated at more hyperpolarized potentials (Spruston and Johnston, 1992; Magee, 1998; Surges et al., 2004). $I_{\mathrm{NaP}}$ is the noninactivating fraction of the sodium conductance, and its activation is strongly voltage dependent at $-57 \mathrm{mV}$, but it is inactive at $-72 \mathrm{mV}$ (French et al., 1990). These currents shape IPSPs and EPSPs in neocortical pyramidal neurons, with $I_{\mathrm{H}}$ accelerating IPSP decay and $I_{\mathrm{NaP}}$ prolonging and amplifying inhibitory potentials in a voltage-dependent manner (van Brederode and Spain, 1995; Stuart, 1999; Williams and Stuart, 2000, 2003). Whether 
they exert the same influences in CA1 pyramidal neurons and whether this depends on synaptic location or intrinsic kinetics remain unknown.

Here, we address these issues using combined current-clamp and voltage-clamp recordings and compartmental modeling. Although their underlying conductance kinetics are quite distinct and show little voltage dependence, the durations of fast somatic versus slow dendritic IPSPs are relatively less distinct and strongly voltage dependent. $I_{\mathrm{H}}$ and $I_{\mathrm{NaP}}$ produce the voltage dependence by opposing actions: at hyperpolarized potentials, $I_{\mathrm{H}}$ accelerates IPSP decay and reduces IPSP amplitude, and at depolarized subthreshold potentials, $I_{\mathrm{NaP}}$ prolongs and amplifies IPSPs. The effect on duration is greater for $\mathrm{GABA}_{\mathrm{A} \text {,fast }}$ and on amplitude is greater for $\mathrm{GABA}_{\mathrm{A} \text {,slow }}$. Thus, passive and active factors influence the temporal impact of synaptic inhibition in CA1 pyramidal neurons in a location- and voltage-dependent manner.

\section{Materials and Methods}

Preparation of slices. Male Sprague Dawley rats (21-32 d of age) were anesthetized with $2 \%$ isoflurane, decapitated, and the heads were immediately immersed in cold $\left(4^{\circ} \mathrm{C}\right)$ saline. The brain was removed, and a midsagittal cut was made to separate the hemispheres. A downward cut was made $2-5 \mathrm{~mm}$ from the posterior end of each hemisphere, displaced from the frontal plane $\sim 15^{\circ}$ toward the anterior and $\sim 35^{\circ}$ toward the midline to obtain a transverse hippocampal section. Brain slices $400-500$ $\mu \mathrm{m}$ thick were cut using a vibrating microtome (VT 10005, Leica, Bannockburn, IL) and transferred to an incubation chamber, where they were maintained submerged at $32^{\circ} \mathrm{C}$ in artificial CSF (ACSF) containing the following (in $\mathrm{mM}$ ): $127 \mathrm{NaCl}, 1.21 \mathrm{KH}_{2} \mathrm{PO}_{4}, 1.87 \mathrm{KCl}, 26 \mathrm{NaHCO}_{3}$, $2.17 \mathrm{CaCl}_{2}, 1.44 \mathrm{MgSO}_{4}, 10$ glucose, saturated with $95 \% \mathrm{O}_{2} / 5 \% \mathrm{CO}_{2}, \mathrm{pH}$ 7.4, with $20 \mu \mathrm{M}$ 6-cyano-7-nitroquinoxaline-2,3-dione (CNQX) and 40 $\mu \mathrm{M}$ 2-amino-5-phosphonovaleric acid (APV). After $45 \mathrm{~min}$, the temperature was lowered to room temperature $\left(22-24^{\circ} \mathrm{C}\right)$, and the slices were maintained under these conditions until they were transferred to a recording chamber perfused with ACSF at $3 \mathrm{ml} / \mathrm{min}$ at elevated temperature $\left(32-34^{\circ} \mathrm{C}\right)$.

Patch-clamp electrophysiology. Neurons in the stratum pyramidale (SP) of CA1 were visualized using a video camera (C2400; Hamamatsu, Hamamatsu City, Japan) connected to an upright microscope (BX50WI; Olympus America, Melville, NY) equipped with an infrared bandpass filter (775 $\pm 75 \mathrm{~nm}$ ), a long working-distance water-immersion objective (40×; numerical aperture, 0.8 ), and differential interference contrast optics. The microscope and recording pipette were positioned using an integrated motorized control system (Luigs and Neumann, Ratingen, Germany).

Whole-cell recordings were obtained using a Multiclamp 700A (Molecular Devices, Union City, CA) patch-clamp amplifier. All data were collected using pClamp 8.0 software (Molecular Devices). Data were filtered at $4 \mathrm{kHz}$, sampled at $10 \mathrm{kHz}$ (Digidata 1200; Molecular Devices), and stored on a Pentium-based computer. Recording pipettes were fabricated from borosilicate glass (KG-33; $1.7 \mathrm{~mm}$ outer diameter, $1.1 \mathrm{~mm}$ inner diameter; Garner Glass, Claremont, CA) using a Flaming-Brown two-stage puller (P-87; Sutter Instruments, Novato, CA). Tight-seal whole-cell recordings were obtained using standard techniques (Hamill et al., 1981; Sakmann et al., 1989). Recording pipettes had open-tip resistances of 2-4 $\mathrm{M} \Omega$ when filled with the recording solution containing the following (in mM): $140 \mathrm{~K}$-gluconate, $10 \mathrm{HEPES}, 5 \mathrm{NaCl}, 4 \mathrm{MgATP}, 10$ phosphocreatine, 0.3 GTP, and 5 EGTA, pH 7.2, and $305 \mathrm{mOsm}$. Access resistances were typically $10-20 \mathrm{M} \Omega$ and were then compensated $60-$

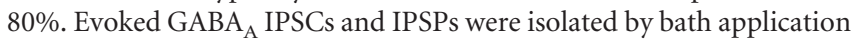
of $20 \mu \mathrm{M}$ CNQX and $40 \mu \mathrm{M}$ APV to block AMPA- and NMDA-mediated currents and by bath application of $2.5 \mu \mathrm{M}$ (2S)-3-([(1s)-1(3,4-dichlorophenyl)ethyl] amino-2-hydroxypropyl)(phenylmethyl)phosphinic acid (CGP 55845A) to block $\mathrm{GABA}_{\mathrm{B}}$-mediated currents. Drugs were allowed $>5 \mathrm{~min}$ to wash in before data collection. For voltage-clamp experiments, cells were held at $-77 \mathrm{mV}$ and stepped to different membrane potentials to characterize evoked IPSC properties.
Blockade of $I_{\mathrm{H}}$ by 4-( $N$-ethyl- $N$-phenylamino)-1,2-dimethyl-6-(methylamino)pyridinum chloride (ZD 7288) was confirmed by monitoring responses to hyperpolarizing current pulses $(0.2-0.5 \mathrm{nA})$. These current pulses resulted in depolarizing sags characteristic of the $I_{\mathrm{H}}$ conductance, with an onset of $40-60 \mathrm{~ms}$ and a peak to steady state voltage difference of $\sim 5 \mathrm{mV}$. A concentration of $20 \mu \mathrm{M}$ ZD 7288 abolished this sag in all cells tested $(n=5)$.

Synaptic responses were evoked using bipolar tungsten electrodes and constant-current stimulus isolation units (A-365; World Precision Instruments, Sarasota, FL) with a maximum stimulation rate of $0.08 \mathrm{~Hz}$. GABA $_{\text {A,fast }}$ was evoked by stimulating $(20-100 \mu \mathrm{A}) \mathrm{SP} \sim 50 \mu \mathrm{m}$ from the recording site. $\mathrm{GABA}_{\mathrm{A} \text {,slow }}$ was evoked by stimulating $(50-300 \mu \mathrm{A})$ at the border between stratum lacunosum-moleculare (SL-M) and stratum radiatum (SR), $\sim 100 \mu \mathrm{m}$ deep in the tissue and displaced 50-100 $\mu \mathrm{m}$ mediolaterally from the apical dendrite of the cell being studied. In some cells, this required that stimulating electrodes be repositioned so that isolated $\mathrm{GABA}_{\mathrm{A} \text {,fast }}$ and $\mathrm{GABA}_{\mathrm{A} \text {,slow }}$ responses could be elicited. For investigations of evoked responses, IPSCs were first characterized in voltage-clamp mode, and the amplifier was then switched to currentclamp mode. IPSPs were then evoked using the same stimulus intensity and electrode positions used during the IPSC characterization. "Injected IPSPs" were obtained by passing current waveforms generated from the $\alpha$ function $I_{\text {inj }}=I_{\max } \times s \times[\exp (-t / \tau$ decay $)-\exp (-t / \tau$ rise $)]$, where $I_{\text {inj }}$ is the current passed through the recording electrode, $I_{\max }$ is the maximal current, and $s$ is a scaling factor so that $I_{\text {inj }}$ is equal to $I_{\max }$ at its peak. The time constants for the fast and slow waveforms were, respectively, $\tau_{\text {rise }}=0.2$ and $3 \mathrm{~ms}$, and $\tau_{\text {decay }}=6$ and $40 \mathrm{~ms}$.

CGP 55845A was a kind gift from Dr. Froestl (CIBA-Giegy, Basel, Switzerland). ZD 7288 was obtained from Tocris Cookson (Bristol, UK). These drugs were prepared directly from their powdered forms and used within $3 \mathrm{~d}$. All other drugs were obtained from Sigma-Aldrich Chemicals (St. Louis, MO) and prepared as stock solutions, frozen, and diluted in ACSF the day of the experiment.

Data analysis. Data were analyzed on a Pentium-based personal computer using ClampFit (Molecular Devices), Origin (OriginLab, Northampton, MA), and MatLab (MathWorks, Natick, MA). In a minority of cases $(<30 \%), \mathrm{GABA}_{\mathrm{A} \text {,slow }}$ was fit well with a single decaying exponential component. The remaining events were fit with the sum of two decaying exponential components, in which case the decay was characterized by the weighted time constant $\tau_{\text {decay, wt }}=\left(A_{1} \tau_{1}+A_{2} \tau_{2}\right) /\left(A_{1}+\right.$ $\left.A_{2}\right)$, where $A_{\mathrm{i}}$ and $\tau_{\mathrm{i}}$ are the amplitude and time constant of decay, respectively, of the $i$ th component. $\mathrm{GABA}_{\mathrm{A} \text {,slow }}$ responses were used if their IPSCs displayed a $10-90 \%$ rise time $>3 \mathrm{~ms}$ and had a monoexponential or weighted $\tau_{\text {decay }}>40 \mathrm{~ms}$. GABA Affast IPSCs decayed biexponentially (Banks et al., 1998) and were characterized as $\tau_{\text {decay, wt }}$. IPSP duration is the time from IPSP peak to 1/e of peak amplitude. Statistical comparisons were made using Student's $t$ tests or two-way ANOVA with Tukey's test for post hoc means comparisons. Differences were considered significant for $\alpha=0.05$. All data are presented as mean \pm SD.

Modeling. Simulations were performed with the compartmental modeling program NEURON (Hines and Carnevale, 1997). The compartmental model was adapted from Poirazi et al. (2003) and run on a personal computer with a Microsoft Windows operating system (Microsoft, Seattle, WA). The cell was a reconstructed CA1 pyramidal cell and included several active membrane mechanisms, with biophysical parameters and spatial distributions based on experimental studies. For most simulations $R_{\mathrm{m}}=45,000 \Omega \cdot \mathrm{cm}^{2}$; however, simulations were also performed using $R_{\mathrm{m}}=65,000 \Omega \cdot \mathrm{cm}^{2}$, and these yield similar results to those reported here. The reversal potential of the leak conductance was set constant at $-75 \mathrm{mV}$, except for simulations in which the membrane potential of the cell was varied (see Fig. 7), in which case the currentbalance function was used to set the reversal potential of the leak conductance to obtain the desired membrane voltage. The model also included Hodgkin-Huxley-type sodium and potassium currents, with $\mathrm{g}_{\mathrm{NaT}, \max }=0$ to simulate sodium channel inactivation at depolarized potentials and resting $V_{\mathrm{m}}$ of $-57 \mathrm{mV}$ without tonic firing. The model included an M-type potassium current, a hyperpolarization-activated current $\left(I_{\mathrm{H}}\right)$ with an increasing density at more distal sites along the apical dendrite (Magee, 1998), T- and L-type calcium currents, and slow 
and medium afterhyperpolarization currents. A-type potassium and R-type calcium currents were present in the original model; however, these currents imparted a dramatic voltage dependence to the input resistance in the absence of $I_{\mathrm{H}}$ and $I_{\mathrm{NaP}}$ that was not observed experimentally, so these were omitted for the simulations shown here.

$\mathrm{GABA}_{\mathrm{A} \text {,fast }}$ and $\mathrm{GABA}_{\mathrm{A} \text {,slow }}$ were modeled with the Exp2Syn point process, of the form $I_{\mathrm{s}}=s \times g_{\mathrm{s}}\left[\exp \left(-t / t_{\text {decay }}\right)-\exp \left(-t / t_{\text {rise }}\right)\right]\left(V_{\mathrm{m}}-\right.$ $\left.E_{\text {rev }}\right)$, where $s$ is the scale factor, $g_{\mathrm{s}}$ is the maximal conductance ( $5 \mathrm{nS}$ for both $\mathrm{GABA}_{\mathrm{A}, \text { fast }}$ and $\left.\mathrm{GABA}_{\mathrm{A} \text {,slow }}\right), t_{\text {rise }}$ was 0.2 and 3 for $\mathrm{GABA}_{\mathrm{A} \text {,fast }}$ and $\mathrm{GABA}_{\mathrm{A}, \text { slow }}$, respectively, and $t_{\text {decay }}$ was 10 and $40 \mathrm{~ms}$ for $\mathrm{GABA}_{\mathrm{A}, \text { fast }}$ and $\mathrm{GABA}_{\mathrm{A} \text {,slow }}$, respectively, $V_{\mathrm{m}}$ is the membrane potential, and the reversal potential of the synapse, $E_{\text {rev }}$, was $-75 \mathrm{mV}$. $\mathrm{GABA}_{\mathrm{A}, \text { fast }}$ was a single point process at the soma, $\mathrm{GABA}_{\mathrm{A} \text {, sow }}$ was distributed evenly over the entire dendritic tree, with a total conductance summed over all synapses equal to $5 \mathrm{nS}$.

Experimental effects of ZD 7288 were simulated by removing the $I_{\mathrm{H}}$ conductance. For simulations in which $I_{\mathrm{H}}$ activation was set constant at steady state, the activation was calculated using the Boltzmann equation with $V_{\mathrm{m}}$ set constant at the baseline membrane potential.

To simulate a persistent sodium conductance, a new mechanism was created, based on experimental parameters determined in entorhinal stellate cells (Magistretti and Alonso, 1999), the activation properties of which are similar to those described in CAl cells (French et al., 1990). Because inactivation properties of $I_{\mathrm{NaP}}$ in CAl pyramidal cells have not been reported, the inactivation properties determined from stellate cells were used. The $I_{\mathrm{NaP}}$ in stellate cells display an inactivation time constant of several seconds, which is sufficiently large compared with the duration of IPSPs (25-100 ms) to model the inactivation as time independent. The level of inactivation was calculated based on the baseline membrane voltage preceding the simulated IPSPs and was then held constant throughout the remainder of the simulation. $I_{\mathrm{NaP}}$ activation is very fast, complete within several milliseconds (French et al., 1990; Crill, 1996), so it was modeled as an instantaneous change in conductance.

The persistent sodium membrane mechanism was of the form $g_{\mathrm{NaP}}=$ $m \times h \times g_{\mathrm{NaP}, \max }$. Activation gate $m=1 /\left(1+\exp \left[\left(V_{1 / 2}-V_{\mathrm{m}}\right) / k\right]\right)$, and inactivation gate $h=1 /\left(1+\exp \left[-\left(V_{1 / 2}-V_{\mathrm{m}}\right) / k\right]\right)$, with the following parameters: activation, $V_{1 / 2}=-52.6 \mathrm{mV}, k=-4.6 \mathrm{mV}$; inactivation, $V_{1 / 2}=-48.8 \mathrm{mV}, k=10 \mathrm{mV}$. The maximal conductance, $g_{\mathrm{NaP}, \max }$, was set at $10 \mu \mathrm{S} / \mathrm{cm}^{2}$, which is within the range of maximal conductances observed physiologically (French et al., 1990; Crill, 1996; Hammarstrom and Gage, 1998). If $I_{\mathrm{A}}$ was not present, then $g_{\mathrm{NaP}, \max }=10 \mu \mathrm{S} / \mathrm{cm}^{2}$ was the maximum conductance that did not result in regenerative sustained depolarizations as $V_{\mathrm{m}}$ approached $-57 \mathrm{mV}$. Including $I_{\mathrm{A}}$ allowed $g_{\mathrm{NaP}, \max }$ to be increased threefold, which is still in the physiological range, and simulations with this conductance level produced results similar to those reported here, excepting a decrease in steady state $R_{\mathrm{N}}$ after depolarization in the absence of $I_{\mathrm{NaP}}$ and $I_{\mathrm{H}}$, which was not observed experimentally with simultaneous TTX and ZD application. $I_{\mathrm{NaP}}$ was distributed evenly throughout the somatic and dendritic compartments, because evidence indicates the presence of $I_{\mathrm{NaP}}$ in CA1 dendrites (French et al., 1990; Lipowsky et al., 1996).

\section{Results}

\section{Characterization of evoked IPSCs versus IPSPs}

Using standard whole-cell patch clamp recording techniques, we studied monosynaptic inhibitory responses in hippocampal CA1 pyramidal neurons. With the amplifier set to voltage-clamp mode, evoked IPSCs (eIPSCs) were obtained at membrane potentials ranging from -115 to $-35 \mathrm{mV}$ (Fig. $1 \mathrm{Ai}, \mathrm{Bi}$ ). As reported previously, $\mathrm{GABA}_{\mathrm{A} \text {, fast }}$ synaptic currents produced by stimulating $\mathrm{SP}$ near the somatic recording site decayed rapidly, with weighted time constants of $\sim 10 \mathrm{~ms}$, whereas $\mathrm{GABA}_{\mathrm{A}, \text { slow }}$ currents evoked by stimulating SL-M decayed more slowly, with weighted time constants between $\sim 35$ and 50 ms. For voltage-clamped eIPSCs, $\mathrm{GABA}_{\mathrm{A} \text {, fast }}$ and $\mathrm{GABA}_{\mathrm{A} \text {,slow }} \tau_{\text {decay }}$ were weakly voltage dependent within the voltage range of -115 to $-30 \mathrm{mV}$, as determined by linear regression (Fig. 1Ci) $(p<0.05)$. GABA ${ }_{\mathrm{A} \text {,fast }} \tau_{\text {decay }}$ increased by e-fold for every $159 \mathrm{mV}$ depolarization, and
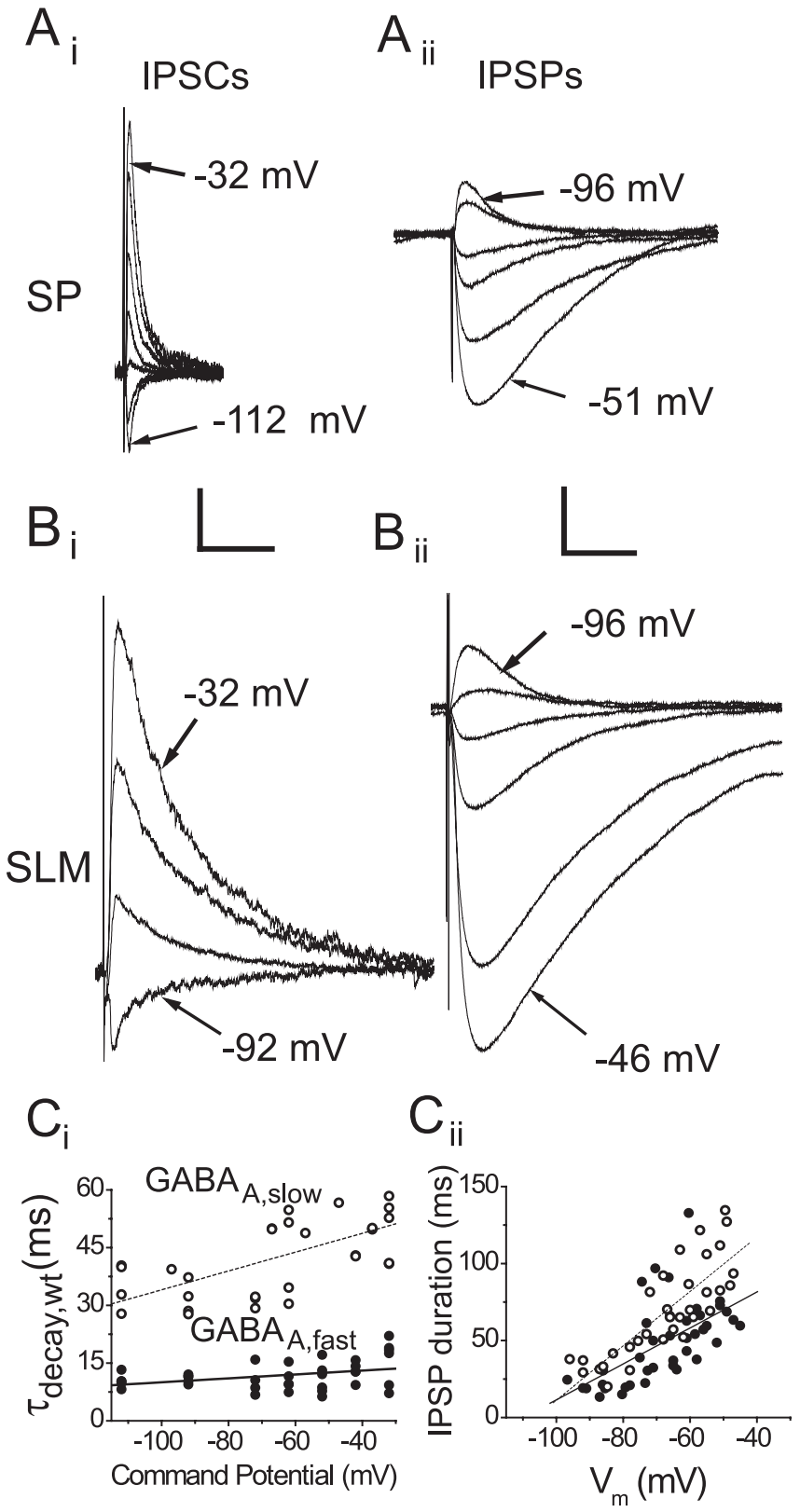

Figure 1. Characterization of evoked $G A B A_{A, \text { fast }}$ and $G A B A_{A, \text { slow }}$ IPSCS and corresponding IPSPs at different voltages. GABA $\mathrm{A}_{\mathrm{A} \text { fast }}(\boldsymbol{A i})$ and $\mathrm{GABA}_{\mathrm{A} \text {, sow }}(\boldsymbol{B} \boldsymbol{i})$ IPSCs were evoked in voltageclamp mode. The recording mode was then switched to current-clamp mode, and the corresponding IPSPs (Aii, Bii) were evoked using the same stimuli. $\boldsymbol{C}$, IPSC weighted $\tau_{\text {decay }}$ at different command voltages for several cells. $\mathrm{GABA}_{\mathrm{A} \text {, fast }}$ (filled symbols) and $\mathrm{GABA}_{\mathrm{A} \text {, slow }}$ (open symbols) IPSC $\tau_{\text {decay,wt }}$ was voltage dependent at membrane potentials from -115 to -30 $\mathrm{mV}\left(p<0.05\right.$, linear regression; depolarization required for e-fold increase of IPSC $\tau_{\text {decay }}$ : $\mathrm{GABA}_{\mathrm{A}, \text { fast}}, 159 \mathrm{mV} ; \mathrm{GABA}_{\mathrm{A}, \text { slow, }}, 138 \mathrm{mV}$ ). Cii, IPSP duration at a range of membrane potentials. $\mathrm{GABA}_{\mathrm{A} \text {, fast }}$ and $\mathrm{GABA}_{\mathrm{A} \text {, slow }}$ IPSP duration was voltage dependent ( $p<0.01$, linear regression; depolarization required for e-fold increase of IPSP duration: $G_{A B A_{A} \text { fast }}, 25.2 \mathrm{mV} ; G_{A B A}$, slow' $20.0 \mathrm{mV}$ ). $n=7$ for $\mathrm{GABA}_{\mathrm{A} \text {, fast }}$ and $n=5$ for $\mathrm{GABA}_{\mathrm{A}, \text { slow. }}$ Calibration: Ai, Bi, $100 \mathrm{pA}, 50 \mathrm{~ms}$; Aii, Bii, 2 mV, 50 ms. SP, Stratum pyramidale; SLM, stratum lacunosum-moleculare.

$\mathrm{GABA}_{\mathrm{A} \text {,slow }}$ increased by e-fold for every $138 \mathrm{mV}$ depolarization, consistent with previous studies which found e-fold increases for

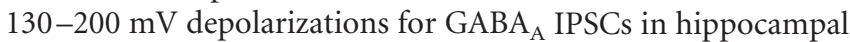
and neocortical neurons (Collingridge et al., 1984; Otis and Mody, 1992; Salin and Prince, 1996).

To examine the properties of the corresponding evoked IPSPs (eIPSPs), we switched the recording mode of the amplifier to 


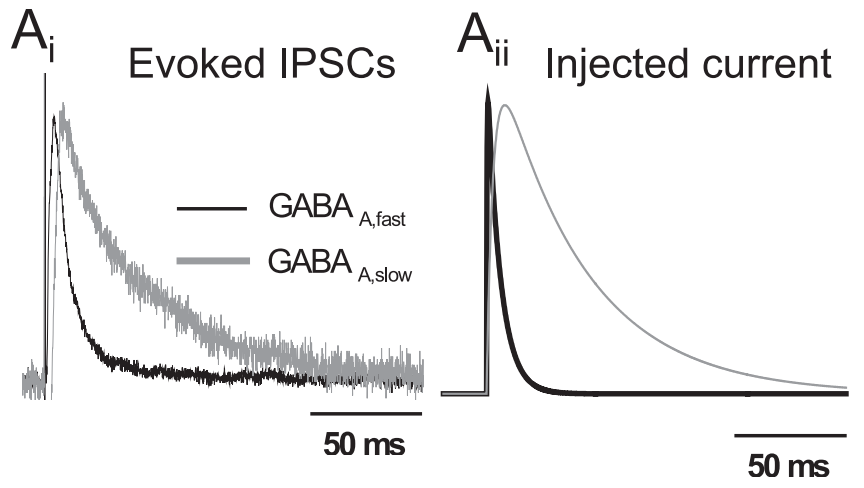

$\mathrm{B}_{\mathrm{i}} \quad$ Evoked IPSPs $\quad \mathrm{B}_{\mathrm{ii}}$ Artificial IPSPs

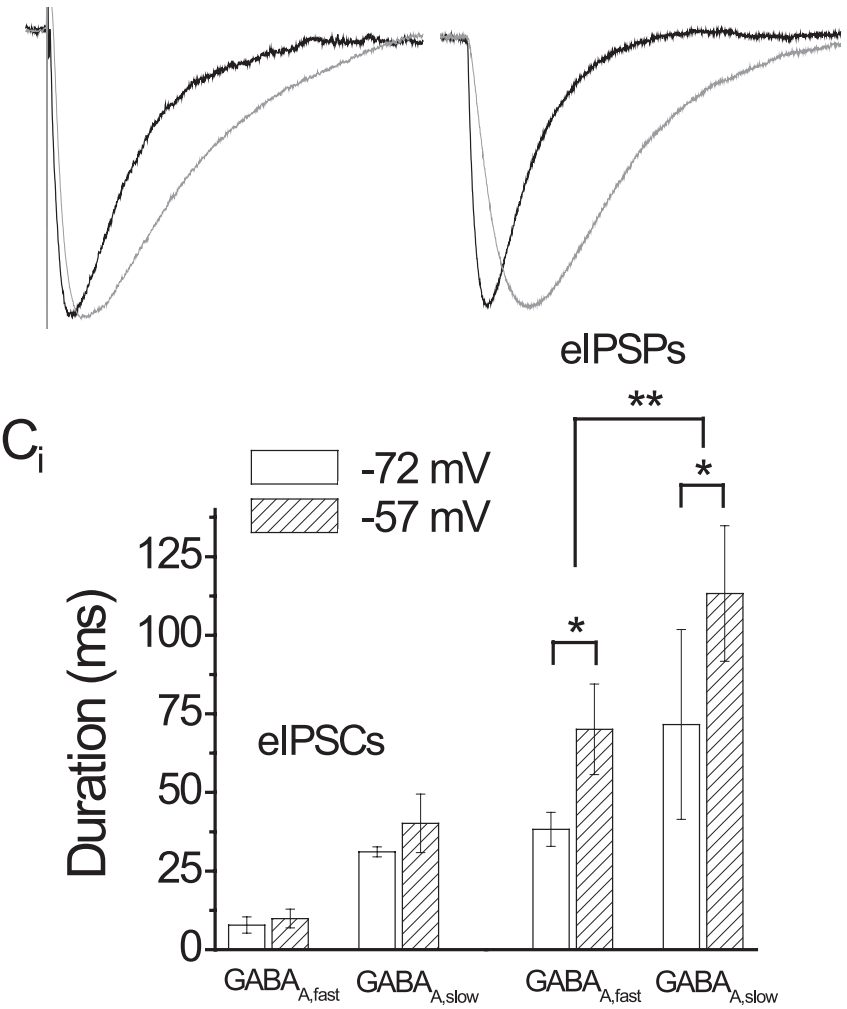

$\mathrm{C}_{\mathrm{ii}}$

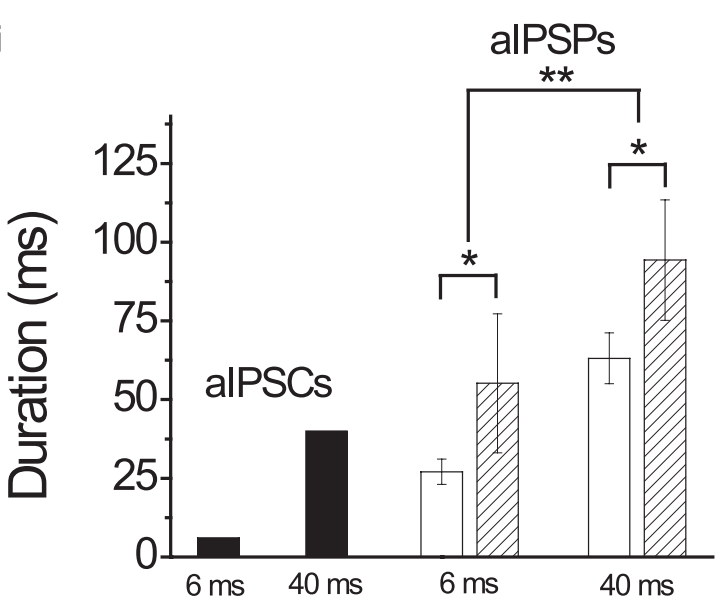

Figure 2. Comparison of evoked and artificial IPSPs. Evoked GABA $A_{A, \text { fast }}$ and $G A B A_{A, \text { slow }}$ IPSCS and IPSPs were characterized in voltage-clamp (Ai) and current-clamp (Aii) modes. Bi, Injected somatic current waveforms with time courses that mimicked $G A B A_{A, \text { fast }}$ and $G A B A_{A, \text { slow }}$ IPSCS. Bii, Artificial IPSPs generated with the GABA $A_{A, \text { fast }}$ and $G A B A_{A, \text { slow }}$ IPSC waveforms. Ci, Summary current-clamp and elicited monosynaptic responses using the same stimuli (Fig. 1 Aii,Bii). Membrane potential was controlled by manually adjusting direct current injection. As expected, SL-M-evoked responses lasted longer than SP-evoked responses (Fig. 1C). However, two other interesting differences were observed between responses in voltage-clamp and current-clamp mode. First, the relative differences in the durations of eIPSPs (Fig. 1Cii) were not nearly as pronounced as the differences in the corresponding eIPSCs (Fig. 1Ci). Second, the degree of voltage dependence of eIPSP durations were sixfold to sevenfold greater than for $\tau_{\text {decay }}$ of eIPSCs (Fig. 1Cii) (depolarization required for e-fold increase in IPSP duration: $\mathrm{GABA}_{\mathrm{A}, \text { fast }}, 25.2 \mathrm{mV}$; $\mathrm{GABA}_{\mathrm{A} \text {,slow }}, 20.0 \mathrm{mV} ; p<0.01$ for both, linear regression).

\section{Effects of membrane potential on IPSP duration}

The substantially greater voltage dependence of IPSPs than IPSCs suggests that in addition to a weak voltage dependence of the underlying synaptic conductance kinetics, other active processes also influence IPSP duration and, in fact, may be primarily responsible for prolonging IPSPs at depolarized potentials. To examine the underlying mechanisms within a physiologically relevant voltage range, in additional experiments, we quantified IPSP properties at membrane potentials of -72 and $-57 \mathrm{mV}$. These two voltages were chosen because $-72 \mathrm{mV}$ is near the resting membrane potential, and $-57 \mathrm{mV}$ was found to be the most depolarized membrane potential that was consistently still subthreshold. Because $E_{\mathrm{Cl}}=-79 \pm 6 \mathrm{mV}$ (determined from $\mathrm{GABA}_{\mathrm{A} \text {,fast }}$ and $\mathrm{GABA}_{\mathrm{A} \text {,slow }}$ IPSC amplitude-voltage relationships; $n=6$ ), eIPSPs were hyperpolarizing at both voltages. Examples of evoked IPSCs and IPSPs at $-72 \mathrm{mV}$ are shown in Figure 2, $A i$ and $B i$, and average characteristics at the two voltages are presented in Figure $2 \mathrm{Ci}$. As expected, both $\mathrm{GABA}_{\mathrm{A} \text {,fast }}$ and $\mathrm{GABA}_{\mathrm{A} \text {,slow }}$ eIPSP durations at $-57 \mathrm{mV}$ were significantly greater than those at $-72 \mathrm{mV}(-57:-72 \mathrm{mV}$ duration ratios, $\mathrm{GABA}_{\mathrm{A} \text {,fast }}=1.8 \pm 0.2, n=7 ; \mathrm{GABA}_{\mathrm{A}, \text { slow }}=1.6 \pm 0.3, n=8 ; p<$ 0.05 , ANOVA). Also, the duration of the $\mathrm{GABA}_{\mathrm{A} \text {,slow }}$ eIPSP was significantly greater than that of $\mathrm{GABA}_{\mathrm{A} \text {,fast }}\left(\mathrm{GABA}_{\mathrm{A} \text {,slow }}\right.$ : $\mathrm{GABA}_{\mathrm{A}, \text { fast }}$ eIPSP duration ratios, $-72 \mathrm{mV}=1.9 \pm 0.3 ;-57 \mathrm{mV}=1.6 \pm 0.2)$, but the difference was not as great as for the corresponding eIPSCs (Fig. 2Ci) $\left(\mathrm{GABA}_{\mathrm{A}, \text { slow }}: \mathrm{GABA}_{\mathrm{A} \text {,fast }}\right.$ eIPSC ratios for duration at 1/e amplitude, $4.4 \pm 1.8$ at $-72 \mathrm{mV}, 4.3 \pm 0.5$ at $-57 \mathrm{mV} ; n=4-8 ; p<0.05$, ANOVA). Thus, the characteristic differences observed over a much greater voltage range (Fig. 1) are also present over this more restricted subthreshold range of membrane potentials.

To determine the degree to which active conductances contribute to the voltage dependence of IPSP duration and to examine the underlying mechanisms, we turned to the study of "artificial IPSPs" (aIPSPs). For these experiments, we injected current waveforms through the somatic recording pipette that matched the characteristics of $\mathrm{GABA}_{\mathrm{A} \text {,fast }}$ and $\mathrm{GABA}_{\mathrm{A} \text {,slow }}$ IPSCs (Fig. 2 Aii) and examined the resulting voltage transients. As expected, aIPSP amplitudes depended strongly on the kinetics of the injected currents, so that to produce comparable IPSP amplitudes at $-72 \mathrm{mV}$ required that the peak amplitude of the $\mathrm{GABA}_{\mathrm{A} \text {,fast }}$ injected waveform be 2.5-fold greater than the peak of the $\mathrm{GABA}_{\mathrm{A} \text {,slow }}$ injected waveform $\left(\mathrm{GABA}_{\mathrm{A} \text {,fast }}, 250 \mathrm{pA}\right.$

\section{$\leftarrow$}

graph of evoked IPSC durations and the resulting IPSP durations at two voltages. GABA $A_{A, \text { sow }}$ IPSP duration was significantly greater than $\mathrm{GABA}_{\mathrm{A} \text {,fast }}$ duration at both -72 and $-57 \mathrm{mV}\left({ }^{* *} p<0.01\right.$, Student's $t$ test), but the relative difference was not as great as that observed for corresponding IPSCs. The durations of both $\mathrm{GABA}_{\mathrm{A} \text {, fast }}$ and $\mathrm{GABA}_{\mathrm{A} \text {, slow }}$ IPSPs increased after depolarization ${ }^{*} p<0.05$, Student's $t$ test). Cii, Artificial GABA ${ }_{A, \text { fast }}$ and $G A B A_{A, s l o w}$ IPSP durations differed significantly (** $p<$ 0.01 , Student's t test). In each case, IPSP duration increased with depolarization from $-72 \mathrm{mV}$ to -57 $\mathrm{mV}\left({ }^{*} p<0.05\right.$, Student's $t$ test). Evoked IPSCs at $-57 \mathrm{mV}: \mathrm{GABA}_{\mathrm{A}, \text { fast }}, n=7$ cells; $\mathrm{GABA}_{\mathrm{A}, \text { slow, }}, n=8$ cells. Evoked IPSCs at $-72 \mathrm{mV}: G_{A B A_{A, \text { fast }}} n=5$; evoked GABA $A_{A, \text { slow' }} n=4$ cells. Injected IISPs: $n=$ 5 cells. Traces shown were normalized averages of three to five traces. Error bars indicate SD. 
peak current injection resulting in $2.8 \pm 0.4 \mathrm{mV}$ IPSP amplitude; $\mathrm{GABA}_{\mathrm{A} \text {,slow }}, 100 \mathrm{pA}$ peak current injection resulting in $-3.3 \pm$ $0.6 \mathrm{mV}$ IPSP amplitude). Using these stimuli, we found that both the fast $\left(\tau_{\text {decay }}=6 \mathrm{~ms}\right)$ and slow $\left(\tau_{\text {decay }}=40 \mathrm{~ms}\right)$ aIPSPs did exhibit voltage-dependent increases in duration (Fig. 2 Bii,Cii) $\left(-57:-72 \mathrm{mV}\right.$ aIPSP duration ratios: $\mathrm{GABA}_{\mathrm{A} \text {,fast }}=2.0 \pm 0.4$, $\left.n=5 ; \mathrm{GABA}_{\mathrm{A} \text {,slow }}=1.5 \pm 0.2, n=5\right)$ that were similar to the voltage dependence of evoked IPSPs (Fig. $2 \mathrm{Bi}, \mathrm{Ci}$ ). Also, as for

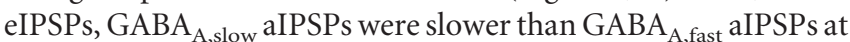
both voltages $\left(\mathrm{GABA}_{\mathrm{A}, \text { slow }}: \mathrm{GABA}_{\mathrm{A} \text {,fast }}\right.$ aIPSP duration ratios: -72 $\mathrm{mV}=2.3 \pm 0.2 ;-57 \mathrm{mV}=1.7 \pm 0.2, n=5 ; p<0.05$; Student's $t$ test). These results thus confirm the presence of voltagedependent mechanisms that alter IPSP duration in CA1 pyramidal neurons, operating at both fast and slow time scales. Furthermore, the similarity between the voltage dependence of evoked IPSPs (Fig. 2Ci) and artificial IPSPs (Fig. 2Cii) indicates that the effects of voltage on IPSP duration are primarily caused by voltage-dependent currents rather than an intrinsic voltage sensitivity of receptor kinetics.

\section{Mechanism of voltage dependence of IPSP duration}

We considered the identities of the active conductances that are responsible for the voltage dependence of IPSPs, focusing primarily on $I_{\mathrm{H}}$ and $I_{\mathrm{NaP}}$. To assess their possible contributions to $\mathrm{GABA}_{\mathrm{A} \text {,fast }}$ and $\mathrm{GABA}_{\mathrm{A} \text {,slow }}$ duration and amplitude, we tested the effects of pharmacological blockade of $I_{\mathrm{H}}$ by $20 \mu \mathrm{m}$ ZD 7288 and blockade of $I_{\mathrm{NaP}}$ by $1 \mu \mathrm{M}$ TTX, using identical current waveforms at the two voltages (Fig. 3). We used aIPSPs for these studies, because a complete block of $I_{\mathrm{NaP}}$ by a high concentration of TTX $(1 \mu \mathrm{M})$ would abolish evoked responses. Also, using aIPSPs allowed us to compare the relative effects of $I_{\mathrm{H}}$ and $I_{\mathrm{NaP}}$ on IPSP amplitudes at different voltages without the confounding influence of a change in driving force.

The membrane potential was maintained at approximately -72 or $-57 \mathrm{mV}$ by manually adjusting the magnitude of injected tonic current, and aIPSPs were generated by injecting current waveforms that mimicked the $\mathrm{GABA}_{\mathrm{A} \text {,fast }}$ and $\mathrm{GABA}_{\mathrm{A} \text {,slow }}$ IPSCs (as illustrated in Fig. 2). IPSP durations at the two voltages were monitored continuously during control periods and after sequential application of ZD 7288 followed by TTX (Fig. 3A), or TTX followed by ZD 7288 (Fig. 3B). As expected, ZD 7288 greatly reduced the voltage-dependent "sag" following hyperpolarizing current injection ( $n=5$; data not shown). When ZD 7288 was applied in the absence of TTX, it also slowed GABA ${ }_{\mathrm{A} \text {,fast }}$ aIPSP decay, but aIPSP duration remained voltage dependent (Fig. $3 A$ ). Subsequent addition of TTX eliminated the voltage dependence by reducing duration to a greater extent at $-57 \mathrm{mV}$ than at -72 $\mathrm{mV}$ (Fig. 3A). Similarly, application of TTX alone eliminated the voltage dependence observed in control conditions, and subsequent addition of ZD 7288 prolonged aIPSP duration at both voltages (Fig. 3B).

Figure 4 summarizes the pharmacological effects on voltage dependence of duration (Fig. $4 A$ ) and amplitude (Fig. $4 B$ ). For both $\mathrm{GABA}_{\mathrm{A} \text {,fast }}\left(\tau_{\text {decay }} 6 \mathrm{~ms}\right)$ and $\mathrm{GABA}_{\mathrm{A} \text {,slow }}\left(\tau_{\text {decay }} 40 \mathrm{~ms}\right)$ waveforms, a strong voltage dependence of duration was present under control conditions and in the presence of ZD $7288(-57:-72$ $\mathrm{mV}$ duration ratios $>1 ; p<0.01$; Student's $t$ test) but absent in TTX ( $p>0.05$; two-way ANOVA). Qualitatively similar results were obtained for pharmacologic sensitivity of aIPSP amplitude, but in this case, ZD 7288 alone did produce a significant effect $\left(p<0.01\right.$; two-way ANOVA). GABA A,fast $_{\text {aIPSP duration was }}$ more strongly voltage dependent than $\mathrm{GABA}_{\mathrm{A} \text {,slow, whereas }}$ $\mathrm{GABA}_{\mathrm{A} \text {,slow }}$ aIPSP amplitude showed a greater voltage depen-
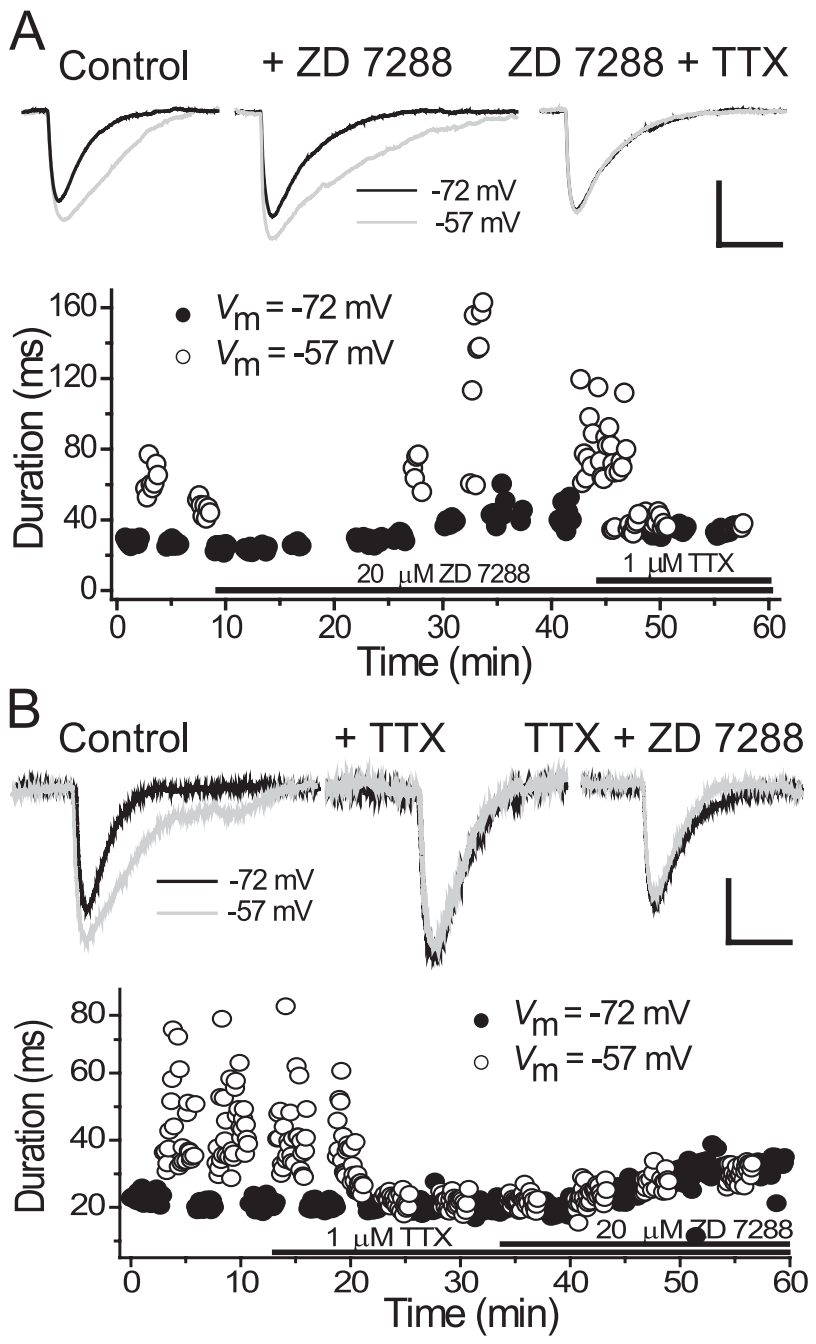

Figure 3. Effects of $I_{\mathrm{H}}$ and $I_{\mathrm{NaP}}$ on duration and amplitude of artificial IPSPS. $\boldsymbol{A}, \mathrm{GABA}_{\mathrm{A}}$ fast aIPSPs were produced by injecting a current waveform matching the time course of the voltageclamped IPSC, at $-57 \mathrm{mV}$ (gray traces) or $-72 \mathrm{mV}$ (black traces). Note the larger response amplitude at $-57 \mathrm{mV}$. Application of ZD $7288(20 \mu \mathrm{m})$ blocked the depolarizing voltage sag during hyperpolarizing current injection (data not shown) and prolonged the IPSP, but IPSP duration remained voltage dependent. Subsequent addition of TTX (1 $\mu \mathrm{m})$ accelerated the IPSP primarily at $-57 \mathrm{mV}$ and reduced the voltage sensitivity of duration or amplitude. Bottom, Time course of pharmacological actions, at $-57 \mathrm{mV}$ (open circles) and $-72 \mathrm{mV}$ (filled circles). $\boldsymbol{B}$, The same experiments as in $\boldsymbol{A}$, except that TTX was applied first followed by ZD 7288. TTX alone greatly diminished the voltage dependence, and addition of ZD 7288 prolonged the duration. Scale bars: vertical, $2 \mathrm{mV}$; horizontal, $50 \mathrm{~ms}$.

dence than $\mathrm{GABA}_{\mathrm{A} \text {,fast }}(p<0.01$; two-way ANOVA). Therefore, intrinsic voltage-dependent conductances increased aIPSP durations and amplitudes, with the fast waveform more strongly augmented in duration and the slow waveform more strongly augmented in amplitude.

To confirm that the above findings derived from studies of aIPSPs also applied to evoked IPSPs, the same experiments illustrated in Figure $3 A$ were conducted using $\mathrm{GABA}_{\mathrm{A} \text {, fast }}$ and $\mathrm{GABA}_{\mathrm{A} \text {,slow }}$ eIPSPs, evoked at $0.05-0.1 \mathrm{~Hz}$ by electrical stimulation. So that synaptic responses could still be obtained, a lower concentration of TTX (100 nM) that would permit action potential conduction but still reduce persistent sodium current was used. As observed for aIPSPs, addition of ZD 7288 prolonged eIPSP durations but did not abolish the voltage dependence (Fig. $5 A$ ). Subsequent application of TTX shortened IPSP durations and greatly reduced their voltage dependence (Fig. $5 B$ ). Figure $5 C$ 


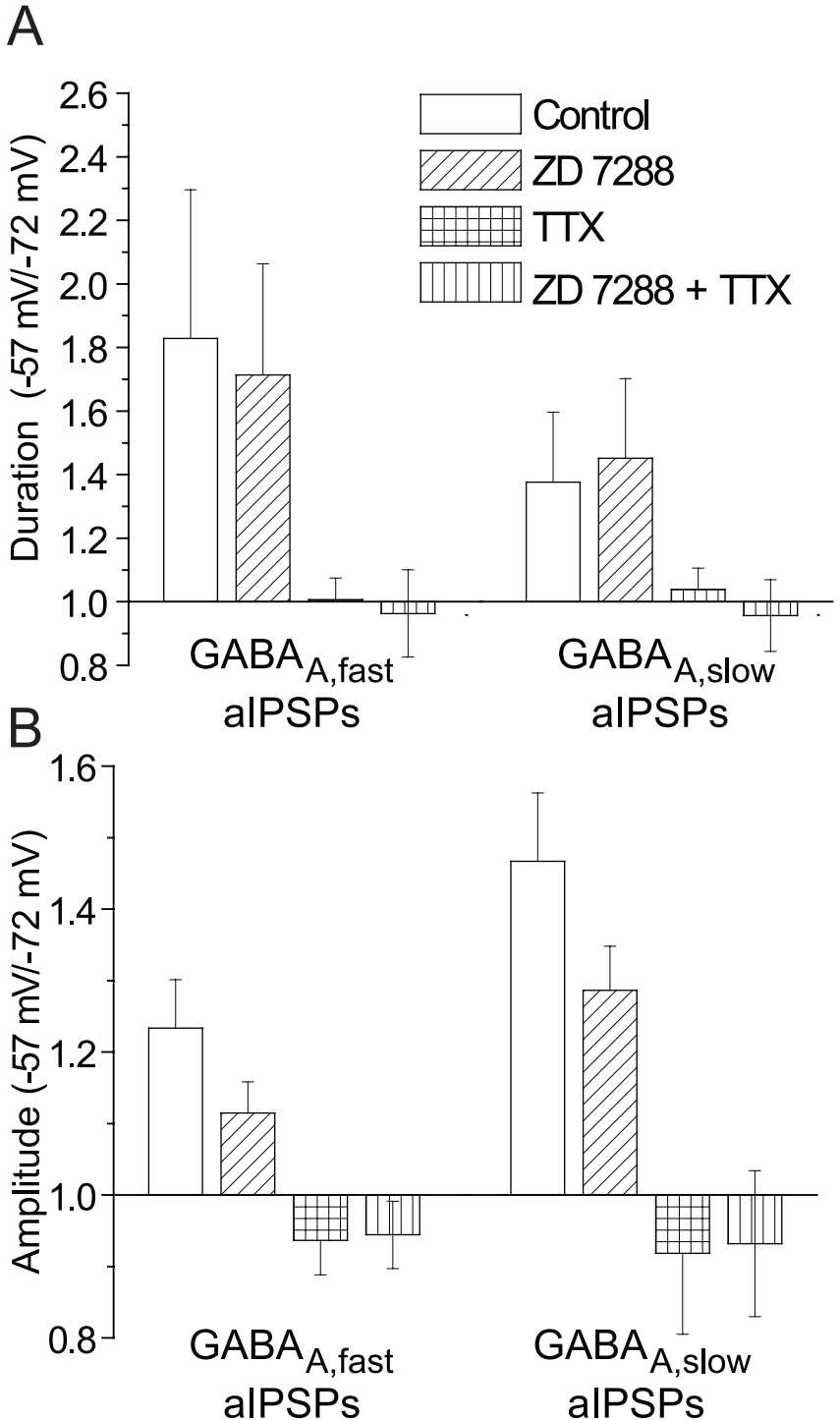

Figure 4. Summary of the effects of $I_{H}$ and $I_{\text {NaP }}$ on voltage dependence of artificial IPSPS. $A$, ZD 7288 alone did not significantly alter the voltage sensitivity of duration, but TTX decreased the voltage sensitivity both in the presence and absence of ZD 7288. Effects of voltage on duration were significantly greater for the fast injected waveform ( $p<0.01$, two-way ANOVA for all comparisons). $\boldsymbol{B}$, Under control conditions, amplitudes of artificial IPSPs were greater at $-57 \mathrm{mV}$ than at $-72 \mathrm{mV}$. Differences were significantly reduced by ZD 7288 and also by TTX. The effects of voltage on amplitude were significantly greater for the slow injected waveform ( $p<0.01$, two-way ANOVA for all comparisons). Error bars indicate SD.

summarizes these effects on duration of $\operatorname{GABA}_{\mathrm{A}, \text { fast }}(n=5)$ and $\mathrm{GABA}_{\mathrm{A}, \text { slow }}(n=4)$ eIPSPs.

We attempted to also confirm the effects of ZD 7288 and TTX on voltage dependence of eIPSP amplitudes by normalizing amplitudes at the two membrane voltages to the magnitude of the driving force of the $\mathrm{GABA}_{\mathrm{A}}$ synaptic currents. However, a substantially greater variability in amplitudes than durations, possibly resulting from intrinsic variation in the number of terminals releasing transmitter with each stimulus, meant that many more evoked responses must be averaged than we were able while maintaining sufficiently stable recording conditions, and this precluded the successful completion of these experiments. Thus, the effects of $I_{\mathrm{H}}$ and $I_{\mathrm{NaP}}$ on IPSP amplitudes reported here are confined to studies using aIPSPs.

Table 1 summarizes the pharmacological effects on duration
A

\section{Control}

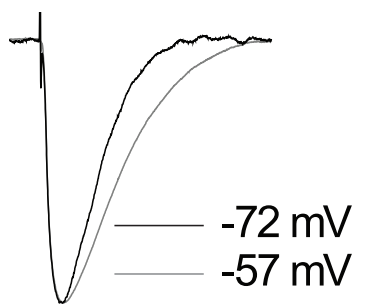

B

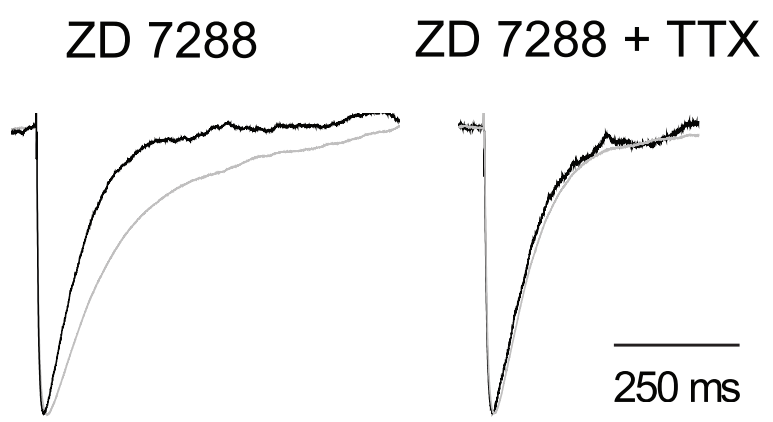

C

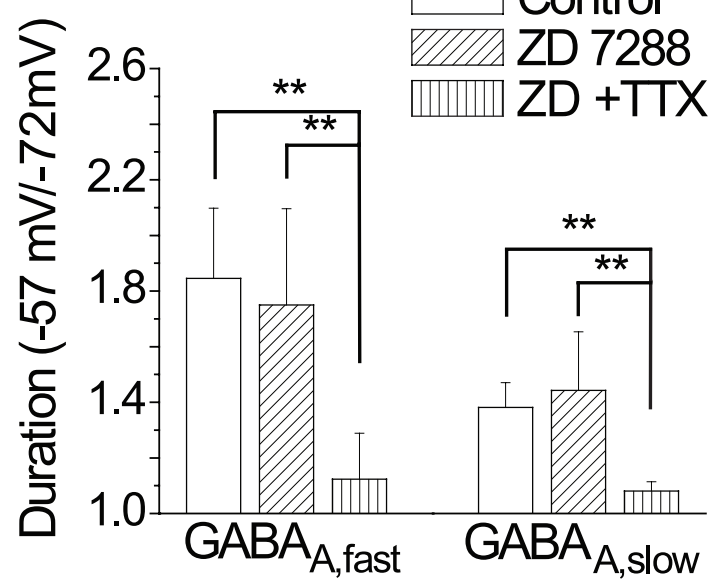

Figure 5. Effects of $I_{\mathrm{H}}$ and $I_{\mathrm{NaP}}$ on duration of evoked IPSPS. A, ZD 7288 prolonged IPSP duration, but IPSPs remained voltage dependent. $\boldsymbol{B}$, In a separate experiment, addition of a low concentration of TTX ( $100 \mathrm{~nm}$ ) to saline containing ZD 7288 accelerated IPSP decay at $-57 \mathrm{mV}$ and greatly decreased the voltage sensitivity. Traces are normalized averages of three to five responses. C, Summary of effects of ZD 7288 and TTX on the voltage dependence of IPSP duration. ZD 7288 alone did not significantly decrease the voltage dependence (two-way ANOVA), but ZD 7288 plus TTX significantly reduced the voltage dependence (** $p<0.01$, two-way ANOVA). As for alPSPs, the duration of $G A B A_{A \text {,fast }}$ was significantly more voltage dependent than the duration of $\mathrm{GABA}_{\mathrm{A} \text { slow }}\left({ }^{* *} p<0.01\right.$, two-way ANOVA). Error bars indicate SD.

and amplitude at -72 and $-57 \mathrm{mV}$. For both eIPSPs and aIPSPs, ZD 7288 prolonged IPSPs to a greater extent at $-72 \mathrm{mV}$ than at $-57 \mathrm{mV}$, whereas TTX accelerated IPSPs more strongly at -57 $\mathrm{mV}$. For aIPSPs, the increase in duration produced by ZD 7288 was significantly greater at $-72 \mathrm{mV}$ than at $-57 \mathrm{mV}$ when TTX was present ( $p<0.05$; two-way ANOVA) but not when TTX was absent (two-way ANOVA). The most consistent effect of TTX on 
Table 1. Effects of TTX and ZD 7288 on IPSP duration and amplitude

\begin{tabular}{|c|c|c|c|c|}
\hline & ZD 7288 & ZD 7288 plus TTX & TTX & TTX plus ZD 7288 \\
\hline \multicolumn{5}{|l|}{ Evoked (elPSPs) } \\
\hline $\mathrm{GABA}_{\mathrm{A}, \text { fast }^{\prime}}-72 \mathrm{mV}$ & $66 \pm 21(5)^{* *}$ & $21 \pm 44(2)$ & NA & NA \\
\hline $\mathrm{GABA}_{\mathrm{A}, \text { fast }^{\prime}}-57 \mathrm{mV}$ & $55 \pm 28(2)$ & $-36 \pm 16(5)^{* *}$ & NA & NA \\
\hline $\mathrm{GABA}_{\mathrm{A}, \text { slow' }}-72 \mathrm{mV}$ & $48 \pm 7(4)^{* *}$ & $-6 \pm 18(4)$ & NA & NA \\
\hline $\mathrm{GABA}_{\mathrm{A}, \text { slow, }}-57 \mathrm{mV}$ & $32 \pm 5(4)^{* *}$ & $-38 \pm 10(4)^{* *}$ & NA & NA \\
\hline \multicolumn{5}{|l|}{ Injected (aIPSPS) } \\
\hline \multicolumn{5}{|l|}{ Duration } \\
\hline $6 \mathrm{~ms},-72 \mathrm{mV}$ & $55 \pm 20(5)^{* *}$ & $-9 \pm 15(6)$ & $-15 \pm 7(8)^{* *}$ & $55 \pm 16(5)^{* *}$ \\
\hline $6 \mathrm{~ms},-57 \mathrm{mV}$ & $32 \pm 52(5)$ & $-45 \pm 14(6)^{* *}$ & $-48 \pm 8(8)^{* *}$ & $29 \pm 18(5)^{* *}$ \\
\hline $40 \mathrm{~ms},-72 \mathrm{mV}$ & $36 \pm 12(5)^{* *}$ & $-4 \pm 8(6)$ & $-4 \pm 5(8)^{*}$ & $45 \pm 9(5)^{* *}$ \\
\hline $40 \mathrm{~ms},-57 \mathrm{mV}$ & $28 \pm 35(5)$ & $-33 \pm 12(6)^{* *}$ & $-31 \pm 9(8)^{* *}$ & $21 \pm 13(5)^{*}$ \\
\hline \multicolumn{5}{|l|}{ Amplitude } \\
\hline $6 \mathrm{~ms},-72 \mathrm{mV}$ & $5 \pm 12(4)$ & $-3 \pm 5(6)$ & $-12 \pm 9(8)^{*}$ & $10 \pm 5(5)$ \\
\hline $6 \mathrm{~ms},-57 \mathrm{mV}$ & $1 \pm 4(4)$ & $-15 \pm 6(6)^{* *}$ & $-34 \pm 11(8)^{*}$ & $8 \pm 6(5)$ \\
\hline $40 \mathrm{~ms},-72 \mathrm{mV}$ & $22 \pm 20(4)$ & $-6 \pm 8(6)$ & $-18 \pm 13(8)^{*}$ & $23 \pm 24(5)$ \\
\hline $40 \mathrm{~ms},-57 \mathrm{mV}$ & $7 \pm 19(4)$ & $-26 \pm 8(6)^{* *}$ & $-48 \pm 11(8)^{*}$ & $18 \pm 11(5)$ \\
\hline
\end{tabular}

Values are expressed as percentage change (\% $\%$ SD) after drug application. Values in parentheses indicate number of cells. ${ }^{* *} p<0.01,{ }^{*} p<0.05 ;$ paired $t$ test (elPSPs) or two-way ANOVA (alPSPs).
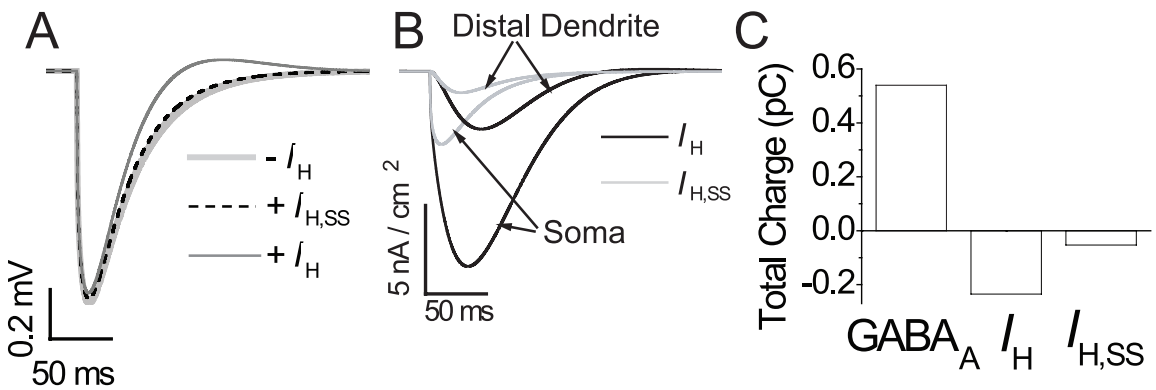

Figure 6. Dynamic shaping of IPSPs by $I_{H}$. $A$, Using a compartmental model implemented in the NEURON simulation environment, IPSPs produced by introduction of a transient conductance waveform with characteristics of $G_{A B A_{A} \text { fast }}$ were compared in the absence of $I_{H}$ (gray trace), in the presence of a time- and voltage-dependent "dynamic" $I_{H}$ (black trace), and in the presence of an added conductance that lacked the time- and voltage-dependent activation and inactivation of $I_{\mathrm{H}}$ but had a constant level of $I_{\mathrm{H}}$ activation calculated from the baseline $V_{\mathrm{m}}\left(I_{\mathrm{H}, \mathrm{SS}} ;\right.$ dotted trace). Introducing $I_{\mathrm{H}, S \mathrm{~S}}$ had little impact on IPSP duration, demonstrating that the effects of $I_{H}$ on duration were caused by dynamic properties of the conductance. $B$, Current densities of the dynamic $I_{H}$ conductance throughout the time course of the IPSP at the soma and in the distal dendrite. $\boldsymbol{C}$, Total charge flowing through the $\mathrm{GABA}_{\mathrm{A}}$ conductance (left), compared with the IPSP-induced charge flowing through a dynamic $I_{H}$ (middle) and time-independent $I_{\mathrm{H}, \mathrm{SS}}$ (right). More than $98 \%$ of the current flowing through the dynamic $I_{\mathrm{H}}$ was located in the dendrites.

duration was a decrease at $-57 \mathrm{mV}$, and this reduction was larger at $-57 \mathrm{mV}$ than at $-72 \mathrm{mV}$ whether $\mathrm{ZD}$ was present or absent $(p<0.05$; ANOVA). The only consistent effect on aIPSP amplitude was a decrease with TTX application. Thus, ZD 7288 prolonged IPSP duration more robustly at $-72 \mathrm{mV}$, and TTX decreased both duration and amplitude more robustly at $-57 \mathrm{mV}$.

\section{NEURON modeling: mechanisms of $I_{\mathrm{H}}$ and $I_{\mathrm{NaP}}$ effects}

Because a significant fraction of $I_{\mathrm{H}}$ conductance is active at the membrane voltages studied here, it is possible that $I_{\mathrm{H}}$ introduces a sufficiently large leak conductance that it influences IPSP duration and amplitude by decreasing input resistance and the membrane time constant. The relative influence of $I_{\mathrm{H}}$ via effects on passive cellular properties resulting from constitutive activation at $-72 \mathrm{mV}$ versus the dynamic shaping of voltage transients is unknown. Because we were unable to separate the relative contributions of active versus passive effects experimentally, we turned to a computational model to address this question.

We used a publicly available NEURON model of a reconstructed CA1 pyramidal cell (Poirazi et al., 2003), which included $I_{\mathrm{H}}$ and supplemented this by an additional $I_{\mathrm{NaP}}$ mechanism (see Materials and Methods for details). This model reproduced the modulation of IPSP duration by both $I_{\mathrm{H}}$ at $-72 \mathrm{mV}$ (Fig. 6A) (simulated $\mathrm{GABA}_{\mathrm{A} \text {,fast }}$ IPSP durations at $-72 \mathrm{mV}$ : $\left.+I_{H}, 34.8 \mathrm{~ms} ;-I_{\mathrm{H}}, 44.9 \mathrm{~ms}\right)$ and $I_{\mathrm{NaP}}$ at $-57 \mathrm{mV}$ (Fig. 6A,C) (simulated $\mathrm{GABA}_{\mathrm{A} \text {,fast }}$ IPSP durations at $-57 \mathrm{mV}$ : $+I_{\mathrm{NaP}}, 88.5 \mathrm{~ms}$; $\left.-I_{\mathrm{NaP}}, 54.9 \mathrm{~ms}\right)$. We used this model to investigate the relative contributions of active shaping versus changes in passive resistance for $I_{\mathrm{H}}$ and the relative contributions of $I_{\mathrm{H}}$ and $I_{\mathrm{NaP}}$ over a range of voltages.

\section{$I_{H}$ : active versus passive shaping of IPSPs}

At $-72 \mathrm{mV}$, the additional steady state tonic $I_{\mathrm{H}}$ conductance may itself have changed the membrane time constant. To test this, the time dependence of activation was removed, without affecting other properties of $I_{\mathrm{H}}$, such as density, distribution, and reversal potential. This was done by setting the $I_{\mathrm{H}}$ conductance constant, based on the activation Boltzmann function, using the baseline membrane voltage of $-72 \mathrm{mV}$. This conductance will hereafter be referred to as $I_{\mathrm{H}, \mathrm{SS}}$, to denote that the $I_{\mathrm{H}}$ conductance activation was held fixed at a given steady state level. Introducing the time-independent $I_{\mathrm{H}}$,ss had little effect on simulated somatic GABA A,fast $_{\text {IPSP du- }}$ ration compared with normal, timedependent $I_{\mathrm{H}}$ (Fig. $6 A$ ). Therefore, most of the effects of $I_{\mathrm{H}}$ on IPSP duration were caused by its dynamic time dependence.

The total change in current density flowing through the dynamic $I_{\mathrm{H}}$ conductance induced by the IPSP was greater than that of $I_{\mathrm{H}, \mathrm{SS}}$ and peaked later during the time course of the IPSP (Fig. 6B) (at the soma, $I_{\mathrm{H}}$ peaks $33 \mathrm{~ms}$ after IPSP onset, $I_{\mathrm{H}, \mathrm{sS}}$ peaks $10 \mathrm{~ms}$ after IPSP onset). Furthermore, the amount of current flowing through the $I_{\mathrm{H}}$ conductance changed substantially during the time course of the IPSP in the distal dendrite (Fig. $6 B$ ), indicating that dendritic $I_{\mathrm{H}}$ may have contributed to the shaping of a somatically generated IPSP.

To confirm that the $I_{\mathrm{H}}$ currents induced by the IPSP were substantial enough to impact IPSP duration, the total membrane charge transfer over the entire cell was measured for the $I_{\mathrm{H}}$ current. This was determined with a membrane mechanism that integrated the $I_{\mathrm{H}}$ current over time in every compartment. The net charge transfer through the $I_{\mathrm{H}}$ conductance induced by the IPSP was determined by comparing identical simulations with and without the IPSP. The current flowing through the GABA conductance was also measured, and the total charge was calculated by integrating this current over time. The charge through the standard dynamic $I_{\mathrm{H}}$ conductance induced by the IPSP was $44 \%$ of the charge flowing through the $\mathrm{GABA}_{\mathrm{A}}$ conductance, whereas the IPSP-induced charge through the time-independent $I_{\mathrm{H}, \mathrm{SS}}$ was only $10 \%$ (Fig. $\left.6 \mathrm{C}\right)\left(\mathrm{GABA}_{\mathrm{A}}\right.$ charge, $0.54 \mathrm{pC}$; $I_{\mathrm{H}}$ charge, $-0.24 \mathrm{pC} ; I_{\mathrm{H}, \mathrm{ss}}$ charge, $\left.-0.05 \mathrm{pC}\right)$. Thus, for $I_{\mathrm{H}}$, a majority of the IPSP-induced charge was a result of dynamic changes in $I_{\mathrm{H}}$ activation during the IPSP. Furthermore, $97 \%$ of this charge was 
attributable to dendritic $I_{\mathrm{H}}$ conductances. Therefore, in the model, the shaping of the duration of the somatically generated IPSP was dominated by current influx through dynamically activated dendritic channels. Thus, we conclude that the experimentally observed effects of $I_{\mathrm{H}}$ on IPSP duration are mostly explained by dynamic shaping of voltage trajectories and not by changes in the passive properties of the cell.

Relative and cooperative effects of $I_{\mathrm{H}}$ and $I_{\mathrm{NaP}}$

Although $I_{\mathrm{H}}$ and $I_{\mathrm{NaP}}$ impart the same type of voltage sensitivity to IPSPs, they do so by complementary actions: $I_{\mathrm{H}}$ shortens IPSPs at more hyperpolarized potentials, whereas $I_{\mathrm{NaP}}$ prolongs IPSPs at more depolarized potentials. To investigate the relative effects of these two conductances as a function of membrane voltage and to test whether the previously characterized biophysical properties of $I_{\mathrm{H}}$ and $I_{\mathrm{NaP}}$ can explain our experimentally observed voltage dependences of IPSP duration and amplitude, we simulated fast and slow synaptic currents at somatic and dendritic locations and measured the durations and amplitudes of the resulting IPSPs as recorded at the soma.

We used a $5 \mathrm{nS}$ maximal conductance for both types of synapses. This conductance was modeled as a single point process at the soma for $\mathrm{GABA}_{\mathrm{A} \text {,fast }}$ and divided throughout the apical compartments as multiple point processes for $\mathrm{GABA}_{\mathrm{A} \text {,slow }}$. The resting potential in all compartments was varied between -73 and $-55 \mathrm{mV}$ by adjusting the passive leak reversal potential. Analysis of $\mathrm{GABA}_{\mathrm{A} \text {,fast }}$ and $\mathrm{GABA}_{\mathrm{A} \text {,slow }}$ IPSPs revealed a voltage dependence of duration (Fig. 7A) and amplitude (Fig. $7 B$ ) in the presence of $I_{\mathrm{H}}$ and $I_{\mathrm{NaP}}$ (Fig. 7, filled symbols). Removal of both $I_{\mathrm{H}}$ and $I_{\mathrm{NaP}}$ greatly reduced and, in fact, reversed this voltage dependence (Fig. 7, open symbols). The pattern of responses thus mimics our experimental observation that there is a greater relative increase in duration than amplitude for $\mathrm{GABA}_{\mathrm{A}, \mathrm{fast}}$, whereas there is a greater increase in amplitude than duration for $\mathrm{GABA}_{\mathrm{A} \text {,slow }}$ (Fig. 4).

The above simulations demonstrate that, together, $I_{\mathrm{H}}$ and $I_{\mathrm{NaP}}$ impart a voltage sensitivity that is similar to that observed experimentally (Fig. 2Ci,Cii). We separated and assessed the individual effects of $I_{\mathrm{H}}$ and $I_{\mathrm{NaP}}$ by simulating IPSPs in the presence and absence of each of these currents. We expressed the effects as the change in duration and amplitude after the removal of either $I_{\mathrm{H}}$ or $I_{\mathrm{NaP}}$ (Fig. $7 C, D$ ). Removal of $I_{\mathrm{H}}$ increased both $\mathrm{GABA}_{\mathrm{A}, \text { slow }}$ and $\mathrm{GABA}_{\mathrm{A} \text {,fast }}$ durations (Fig. $7 \mathrm{C}$ ) but had a much greater impact on $\mathrm{GABA}_{\mathrm{A}, \text { slow }}$ than $\mathrm{GABA}_{\mathrm{A} \text {, fast }}$ at hyperpolarized potentials. In contrast, removal of $I_{\mathrm{NaP}}$ reduced IPSP durations, and the effects were strongest at depolarized potentials and greater for $\mathrm{GABA}_{\mathrm{A} \text {,fast }}$ than $\mathrm{GABA}_{\mathrm{A} \text {,slow. }}$ These results are consistent with the experimental observation that $I_{\mathrm{NaP}}$ is mostly responsible for imparting the voltage sensitivity to IPSP duration, and that the relative effects are greater for $\mathrm{GABA}_{\mathrm{A}, \text { fast }}$ than $\mathrm{GABA}_{\mathrm{A} \text { slow }}$ (Figs. $4 A, 5$ ).

Surprisingly, for both $\mathrm{GABA}_{\mathrm{A}, \text { fast }}$ and $\mathrm{GABA}_{\mathrm{A} \text {,slow }}$ the effect of $I_{\mathrm{H}}$ on duration was almost as large at some depolarized potentials as it was at hyperpolarized potentials (Fig. $7 C$, arrow). This effect was caused by an interaction between $I_{\mathrm{H}}$ and $I_{\mathrm{NaP}}$, because in a model lacking $I_{\mathrm{NaP}}$, the removal of $I_{\mathrm{H}}$ resulted in a monotonic pattern of changes, with greater effects at hyperpolarized potentials (Fig. 7E). Thus, these two conductances had synergistic interactions that allowed $I_{\mathrm{H}}$ to influence IPSP duration similarly throughout the entire voltage range. This interaction may account for our experimental observation that application of ZD 7288 slowed IPSPs but did not strongly affect their voltage sensitivity (Figs. 3, 4A, 5).

In contrast to its effects on duration, $I_{\mathrm{NaP}}$ more strongly af-
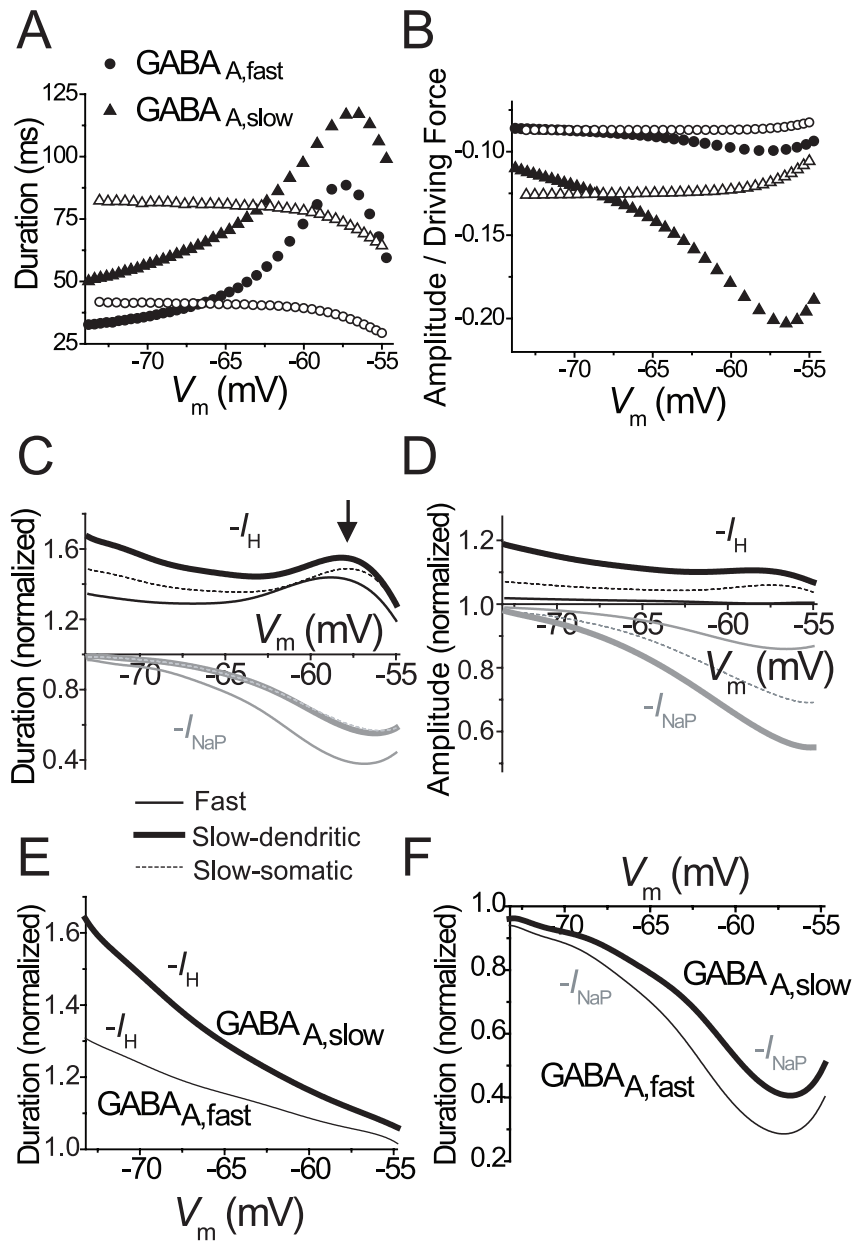

Figure 7. Effects of $I_{H}$ and $I_{\text {NaP }}$ on simulated $G A B A_{A, \text { fast }}$ and $G A B A_{A, \text { slow }}$ IPSP duration and amplitude. $A$, For both $G A B A_{A, \text { fast }}$ and $G A B A_{A, \text { slow }}$ IPSPS, duration was strongly voltage dependent under control conditions (filled symbols). Voltage dependence was reduced and reversed after removal of both $I_{H}$ and $I_{\text {NaP }}$ (open symbols). $B$, IPSP amplitude, normalized for driving force, was more strongly voltage dependent for $G A B A_{A, \text { slow }}$ than $G A B A_{A, \text { fast }}$ under control conditions (filled symbols). Voltage dependence was reduced and reversed after removal of $I_{H}$ and $I_{\mathrm{NaP}}$ (open symbols). $\boldsymbol{C}, \boldsymbol{D}$, Characterization of relative effects of $I_{\mathrm{H}}$ and $I_{\mathrm{NaP}}$ on duration $(\boldsymbol{C})$ and amplitude (D), expressed as the fractional change induced by removal of each conductance individually. Removal of $I_{H}$ altered duration at depolarized as well as hyperpolarized potentials, suggesting interactions of the $I_{\mathrm{H}}$ and $I_{\mathrm{NaP}}$ currents (arrow). The location of $\mathrm{GABA}_{\mathrm{A} \text {, slow }}$ in the dendrites (solid black trace, compare with conductance with slow kinetics located at the soma, dotted trace) influenced the impact of $I_{H}$ on voltage dependence of duration $(\boldsymbol{C})$ and of both $/ \mathrm{NaP}$ and $I_{H}$ on voltage dependence of amplitude $(\boldsymbol{D})$. $E$, In the absence of $I_{\mathrm{Nap}}$, removal of $I_{\mathrm{H}}$ slowed IPSP decay more strongly at hyperpolarized potentials (compare with $\boldsymbol{C},-I_{H}$ ). $\boldsymbol{F}$, In the absence of $I_{\mathrm{H}}$, removal of $I_{\mathrm{NaP}}$ accelerated IPSP decay more strongly at depolarized potentials. Note that this effect is slightly greater than in the presence of $I_{\mathrm{H}}$ (compare with $\left.C,-I_{\text {NaP }}\right)$.

fected the amplitude of $\mathrm{GABA}_{\mathrm{A} \text {,slow }}$ than $\mathrm{GABA}_{\mathrm{A} \text {,fast }}$ at all voltages (Fig. 7D), and its effects were greater at more depolarized potentials. Similar to its effect on duration, $I_{\mathrm{H}}$ more strongly affected the amplitude of $\mathrm{GABA}_{\mathrm{A} \text {,slow }}$ than $\mathrm{GABA}_{\mathrm{A} \text {,fast }}$. Thus, the individual effects of both $I_{\mathrm{H}}$ and $I_{\mathrm{NaP}}$ on amplitudes were greater for $\mathrm{GABA}_{\mathrm{A} \text {,slow }}$ than $\mathrm{GABA}_{\mathrm{A} \text {,fast }}$.

\section{Influence of location versus kinetics of $\mathrm{GABA}_{\mathrm{A} \text {,slow }}$}

To determine whether the dendritic location of $\mathrm{GABA}_{\mathrm{A} \text {,slow }}$ contributed to the differences in voltage-dependent effects of $I_{\mathrm{H}}$ and $I_{\mathrm{NaP}}$ on $\mathrm{GABA}_{\mathrm{A}, \text { slow }}$ versus $\mathrm{GABA}_{\mathrm{A} \text {,fast }}$ IPSPs, we implemented a somatic conductance with $\mathrm{GABA}_{\mathrm{A} \text {,slow }}$ kinetics. In most cases, the effects of $I_{\mathrm{NaP}}$ and $I_{\mathrm{H}}$ on somatic GABA $\mathrm{A}_{\text {,slow }}$ amplitude and duration were intermediate to the effects of somatic $\mathrm{GABA}_{\mathrm{A} \text {,fast }}$ and 
dendritic $\mathrm{GABA}_{\mathrm{A} \text {,slow }}$ (Fig. 7C,D). This indicates that both location and underlying kinetics contributed to the differences between effects on $\mathrm{GABA}_{\mathrm{A} \text {,fast }}$ and $\mathrm{GABA}_{\mathrm{A} \text {,slow. }}$. The one exception to this finding was the effect of $I_{\mathrm{NaP}}$ on duration, in which case synaptic location did not have an influence. This finding is reminiscent of our experimental observation that evoked (dendritic) $\mathrm{GABA}_{\mathrm{A} \text {,slow }}$ and somatically injected $\mathrm{GABA}_{\mathrm{A} \text {,slow }}$ waveforms displayed similar voltage dependencies (Fig. $5 A, B$ ). Again, this result suggests that effects of voltage on IPSP duration are primarily mediated by $I_{\mathrm{NaP}}$. In the model, $I_{\mathrm{NaP}}$ exerted a greater effect on duration at depolarized potentials in the absence of $I_{\mathrm{H}}$ than in its presence (Fig. 7, compare $F$ and $C$ ), indicating that $I_{\mathrm{H}}$ is to some extent able to counteract the effects of $I_{\mathrm{NaP}}$. As in the presence of $I_{\mathrm{H}}$, removal of $I_{\mathrm{NaP}}$ in the absence of $I_{\mathrm{H}}($ Fig. $7 F)$ had a markedly greater effect on duration at depolarized than hyperpolarized potentials and thereby imparted a pronounced voltage dependence.

The model predicts that in the absence of TTX, $I_{\mathrm{H}}$ should have a relatively modest effect on the voltage dependence of duration (duration at $-57 /$ duration at $-72 \mathrm{mV}$ decreased from $1.0-0.84$ after removal of $I_{\mathrm{H}}$ for $\mathrm{GABA}_{\mathrm{A} \text {,fast, }}$, and from 1.3-0.88 for $\left.\mathrm{GABA}_{\mathrm{A} \text {,slow }}\right)$. For cells in which ZD 7288 was added in the presence of TTX, we did observe significant decreases in voltage dependence of duration for aIPSPs (duration at -57 /duration at $-72 \mathrm{mV}$ decreased from $1.00 \pm 0.07$ to $0.83 \pm 0.07$ with $\mathrm{ZD}$ application for $\mathrm{GABA}_{\mathrm{A} \text {,fast }}, p<0.01$, paired $t$ test; and from $1.04 \pm 0.07$ to $0.85 \pm 0.08$ for $\mathrm{GABA}_{\mathrm{A} \text {,slow }}, p<0.01$, paired $t$ test $)$. Application of ZD 7288 in the absence of TTX did not result in a detectable change of voltage dependence ( $p>0.05$; paired $t$ test $)$, consistent with the "boosting" of $I_{\mathrm{H}}$ by $I_{\mathrm{NaP}}$ at depolarized potentials (Fig. 7C). Thus, the experimentally measured changes in voltage dependence produced by ZD 7288 and TTX support the findings of the model regarding the relative and cooperative effects of $I_{\mathrm{H}}$ and $I_{\mathrm{NaP}}$.

\section{Discussion}

Past studies using voltage-clamp recordings to compare the physiological properties of fast somatic versus slow dendritic inhibitory synapses revealed substantial differences in conductance kinetics, with somatic IPSCs approximately fourfold to sevenfold faster than dendritic IPSCs depending on the experimental temperature $\left(\mathrm{GABA}_{\mathrm{A} \text {,fast }}\right.$ has a higher $\mathrm{Q}_{10}$ than $\left.\mathrm{GABA}_{\mathrm{A}, \text { slow }}\right)$ (Banks et al., 1998). Our present results demonstrate that passive and active properties strongly influence the resulting synaptic potentials, serving to reduce the dissimilarity in their duration and to prolong IPSPs at depolarized voltages.

\section{Passive properties minimize differences in IPSP duration}

We showed previously that the difference in duration of $\mathrm{GABA}_{\mathrm{A} \text {,fast }}$ versus $\mathrm{GABA}_{\mathrm{A} \text {,slow }}$ IPSCs is not simply the result of space clamp artifact, because there are equivalent differences in the kinetics of the underlying synaptic conductances (Pearce, 1993). The smaller difference under current-clamp conditions, $\sim 1.5$-fold to twofold, is primarily a consequence of the slow $(\tau$ $\sim 20-30 \mathrm{~ms}$ ) membrane time constant of CA1 pyramidal cells (Spruston et al., 1992). Because $\tau_{\text {decay }}$ of $\mathrm{GABA}_{\mathrm{A} \text {,fast }}(\sim 6 \mathrm{~ms})$ is faster than the membrane time constant, it is prolonged to a greater fractional extent than $\operatorname{GABA}_{\mathrm{A} \text {,slow }}\left(\tau_{\text {decay }} \sim 40 \mathrm{~ms}\right)$.

\section{Active properties produce voltage-dependent IPSP duration}

The decay rate of inhibitory currents was only weakly voltage dependent (Fig. 1) and approximately the same for $\mathrm{GABA}_{\mathrm{A} \text {,fast }}$ and $\mathrm{GABA}_{\mathrm{A} \text {,slow }}$ IPSCs (e-fold change over 138 and $159 \mathrm{mV}$ ), similar to previous reports (Collingridge et al., 1984; Otis and
Mody, 1992; Jones and Harrison, 1993; Salin and Prince, 1996). In contrast, IPSP duration was strongly voltage dependent (e-fold change over 25 and $20 \mathrm{mV}$ ). Whereas passive properties reduced differences in IPSP durations, active conductances produced the voltage dependence. The effect was not small: its magnitude was equivalent to changes brought about by threefold to sixfold changes in the decay of synaptic conductances (Fig. 2).

The combined influences of $I_{\mathrm{NaP}}$ and $I_{\mathrm{H}}$ produced slower and larger IPSPs at more depolarized potentials. These results are similar to the findings that IPSPs in neocortical neurons are prolonged by $I_{\mathrm{NaP}}$ after depolarization from -80 to $-50 \mathrm{mV}$ (Williams and Stuart, 2003) and that $I_{\mathrm{H}}$ accelerates IPSP decay at hyperpolarized potentials (van Brederode and Spain, 1995). Our present results extend these findings by showing that: (1) the effects are also present in CA1 neurons; (2) they are substantial even over a smaller $(15 \mathrm{mV})$ voltage range varying from rest to threshold; (3) they are observed with evoked synaptic responses as well as artificially imposed currents or conductances; and (4) influences on physiologically distinct inhibitory synapses are qualitatively similar but differ quantitatively.

\section{Static versus dynamic influences on IPSP duration}

Based solely on passive properties, it might be expected that blocking a membrane conductance would increase the input resistance and thereby increase amplitude and prolong IPSPs ( $\tau=$ RC). However, we found that TTX paradoxically reduced IPSP duration and amplitude (Table 1). It was such a paradoxical effect that caused $I_{\mathrm{NaP}}$ initially to be termed an "anomalous rectifying" current (Hotson et al., 1979). The explanation for amplitude effects is straightforward: a fraction of a tonic $I_{\mathrm{NaP}}$ conductance is turned off as the IPSP hyperpolarizes the membrane, and this augments the IPSP. The rapid kinetics of $I_{\mathrm{NaP}}$ activation and deactivation are an essential characteristic allowing rapid changes in channel activity during the IPSP. The effect on duration is less intuitive, but it is clearly reproduced in the computational model (Fig. 7C).

In the case of $I_{\mathrm{H}}$, activation and deactivation kinetics are relatively slower. Thus, we considered how changes in this current contributed to the effect of $I_{\mathrm{H}}$ on duration. Compartmental modeling showed that a nonchanging "leak" (a "static" effect) produced only minor changes in IPSPs (Fig. 6A). Thus, the primary effects of $I_{\mathrm{H}}$ are through "dynamic" changes of $I_{\mathrm{H}}$ activation level during the time course of the IPSP.

Other investigators have found that $I_{\mathrm{H}}$ shapes dendritic voltage transients (Magee, 1998; Williams and Stuart, 2003). Interestingly, using compartmental modeling, we found that $I_{\mathrm{H}}$ in the dendrites is almost entirely responsible for the observed effects of $I_{\mathrm{H}}$ on duration even for IPSPs generated entirely at the soma. Thus, dendritic $I_{\mathrm{H}}$ is important for integration throughout the somatodendritic axis in these neurons.

\section{Passive versus active influences on IPSP amplitude}

Passive membrane properties influence IPSP amplitudes in two ways. First, for synaptic currents briefer than the membrane time constant, the duration of the IPSC influences the amplitude of the resulting IPSP. Thus, in our experiments with aIPSPs, it was necessary to inject current 2.5-fold larger for fast synapses to achieve the same amplitudes as slow synapses. A second passive influence is that of driving force. Given the reversal potential of $-79 \mathrm{mV}$ that we measured, this would cause IPSPs to be approximately three times larger at $-57 \mathrm{mV}$ than at $-72 \mathrm{mV}$.

How does the magnitude of the passive effect of voltage on IPSP amplitude compare with that produced by active mem- 
brane properties? Using aIPSPs, we characterized the influences of $I_{\mathrm{H}}$ and $I_{\mathrm{NaP}}$ on IPSP amplitudes. As opposed to their greater influence on the duration of $\mathrm{GABA}_{\mathrm{A} \text {,fast }}$ than $\mathrm{GABA}_{\mathrm{A} \text {,slow, }}$, these active conductances caused a greater amplification of $\mathrm{GABA}_{\mathrm{A} \text {,slow }}$ aIPSP amplitude than $\mathrm{GABA}_{\mathrm{A} \text {,fast }}$ (Fig. 4). Still, even for $\mathrm{GABA}_{\mathrm{A} \text {,slow }}, I_{\mathrm{NaP}}$ and $I_{\mathrm{H}}$ together only increased amplitude by $50 \%$. Thus, compared with the $300 \%$ increase in amplitude expected from the change in driving force, the contributions of active conductances to amplitude amplification are relatively small.

\section{IPSPs and the functional impact of inhibition}

In some circumstances, for example, when inhibition is superimposed on a tonic excitatory influence, the primary influence of inhibition will be via hyperpolarization. Under other circumstances, such as in a resting and hyperpolarized cell, IPSPs may actually have a depolarizing influence that facilitates action potential firing (Gulledge and Stuart, 2003). In either case, the timing of action potentials following IPSPs will be subject to the influences of passive and active membrane properties that we describe here. Because inhibition plays an important role in synchronization of neuronal networks (Soltesz and Deschenes, 1993; Ylinen et al., 1995; Penttonen et al., 1998), the active conductances that influence IPSPs may thereby also influence neuronal synchrony and determine spike timing, for example, during phase precession of place cell activity during locomotion (Harris et al., 2002). Given the critical role of spike timing in determining the strength and direction of changes in synaptic strength (Markram et al., 1997; Bi and Poo, 1998), $I_{\mathrm{H}}$ and $I_{\mathrm{NaP}}$ may also thereby influence synaptic plasticity.

If passive membrane properties minimize differences in the duration of $\mathrm{GABA}_{\mathrm{A} \text {,fast }}$ and $\mathrm{GABA}_{\mathrm{A} \text {,slow }}$ IPSPs, then under what circumstances might the difference in their IPSC kinetics come into play? The durations of the underlying conductances, as well as relative locations of inhibitory and excitatory synapses, determine the temporal window during which inhibition attenuates action potential firing (Vida et al., 2006) or regulates facilitation of dendritic NMDA responses to burst stimulation (Kanter et al., 1996). One scenario in which the more rapid decay of the fast somatic conductance may matter is during nested $\theta-\gamma$ oscillations. Here, bouts of synchronous IPSCs impinge on pyramidal cells at $\gamma$ frequency $(\sim 40 \mathrm{~Hz})$, and these bouts of somatic inhibition recur at $\theta$ frequency $(8 \mathrm{~Hz})$. Curiously, it is during the phase of the $\theta$ oscillation when somatic-targeting basket cells firing rate is greatest, and $\gamma$ oscillations are largest, that pyramidal cells fire most strongly in awake behaving animals (Fox et al., 1986; Bragin et al., 1995; Skaggs et al., 1996; Csicsvari et al., 1999). This occurs despite the fact that the interval between IPSCs $(\sim 25 \mathrm{~ms})$ is substantially briefer than the fast IPSP duration $(\sim 50 \mathrm{~ms}$ at -60 $\mathrm{mV}$ ). Thus, just as shunting inhibition facilitates synchronous firing of inhibitory interneuron networks to generate $\gamma$ oscillations (Vida et al., 2006), it also constrains the timing of action potentials in pyramidal neurons so that firing is strongly phase locked to the $\gamma$ oscillation (Penttonen et al., 1998b).

The slower time course of dendritic inhibition may analogously serve to shunt local excitatory inputs during $\theta$ oscillations. Dendrite-targeting interneurons are most active out of phase with basket cell activity (Klausberger et al., 2003, 2004); i.e., dendrites are most strongly depolarized when the soma is inhibited, and the dendrites are most strongly inhibited as basket cell firing wanes (Kamondi et al., 1998). It has been proposed that this curious "see-saw" timing of inhibitory synaptic input permits encoding and retrieval during different phases of theta activity
(Kunec et al., 2005). The slow time course of dendritic inhibition may be an important characteristic that supports this function, and its interplay with active currents that modify the level and duration of hyperpolarization may contribute to its ability to control dendritic polarization and synaptic plasticity.

Whether inhibitory synapses exert their effects via hyperpolarization or shunting, it is apparent that differences between fast somatic and slow dendritic inhibition contribute to differences in their ability to control integrative function and spike timing. In this way, they contribute to the ability of the hippocampus to use coding strategies that rely on spike timing to perform its critical roles in learning and memory and in other aspects of higher cognitive function.

\section{References}

Banks MI, Li TB, Pearce RA (1998) The synaptic basis of $\mathrm{GABA}_{\mathrm{A}}$, slow. J Neurosci 18:1305-1317.

Bi GQ, Poo MM (1998) Synaptic modifications in cultured hippocampal neurons: dependence on spike timing, synaptic strength, and postsynaptic cell type. J Neurosci 18:10464-10472.

Bragin A, Jando G, Nadasdy Z, Hetke J, Wise K, Buzsaki G (1995) Gamma $(40-100 \mathrm{~Hz})$ oscillation in the hippocampus of the behaving rat. J Neurosci 15:47-60.

Cobb SR, Buhl EH, Halasy K, Paulsen O, Somogyi P (1995) Synchronization of neuronal activity in hippocampus by individual gabaergic interneurons. Nature 378:75-78.

Collingridge GL, Gage PW, Robertson B (1984) Inhibitory post-synaptic currents in rat hippocampal CA1 neurones. J Physiol (Lond) 356:551-564.

Crill WE (1996) Persistent sodium current in mammalian central neurons. Annual Rev of Physiology 58:349-362.

Csicsvari J, Hirase H, Czurko A, Mamiya A, Buzsaki G (1999) Oscillatory coupling of hippocampal pyramidal cells and interneurons in the behaving rat. J Neurosci 19:274-287.

Davies CH, Collingridge GL (1996) Regulation of EPSPs by the synaptic activation of GABA(B) autoreceptors in rat hippocampus. J Physiol (Lond) 496:451-470.

Evans MS, Viola-McCabe KE (1996) Midazolam inhibits long-term potentiation through modulation of GABAA receptors. Neuropharmacology 35:347-357.

Fox SE, Wolfson S, Ranck Jr JB (1986) Hippocampal theta rhythm and the firing of neurons in walking and urethane anesthetized rats. Exp Brain Res 62:495-508.

French CR, Sah P, Buckett KJ, Gage PW (1990) A voltage-dependent persistent sodium current in mammalian hippocampal neurons. J Gen Physiol 95:1139-1157.

Gulledge AT, Stuart GJ (2003) Excitatory actions of GABA in the cortex. Neuron 37:299-309.

Hamill OP, Marty A, Neher E, Sakmann B, Sigworth FJ (1981) Improved patch-clamp techniques for high-resolution current recording from cells and cell-free membrane patches. Pflügers Arch 391:85-100.

Hammarstrom AK, Gage PW (1998) Inhibition of oxidative metabolism increases persistent sodium current in rat CA1 hippocampal neurons. J Physiol (Lond) 510:735-741.

Harris KD, Henze DA, Hirase H, Leinekugel X, Dragoi G, Czurko A, Buzsaki G (2002) Spike train dynamics predicts theta-related phase precession in hippocampal pyramidal cells. Nature 417:738-741.

Hausser M, Spruston N, Stuart GJ (2000) Diversity and dynamics of dendritic signaling. Science 290:739-744.

Hines ML, Carnevale NT (1997) The NEURON simulation environment. Neural Comput 9:1179-1209.

Hotson JR, Prince DA, Schwartzkroin PA (1979) Anomalous inward rectification in hippocampal neurons. J Neurophysiol 42:889-895.

Jones MV, Harrison NL (1993) Effects of volatile anesthetics on the kinetics of inhibitory postsynaptic currents in cultured rat hippocampal neurons. J Neurophysiol 70:1339-1349.

Kamondi A, Acsady L, Wang XJ, Buzsaki G (1998) Theta oscillations in somata and dendrites of hippocampal pyramidal cells in vivo: activitydependent phase-precession of action potentials. Hippocampus $8: 244-261$. 


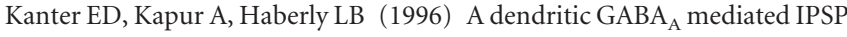
regulates facilitation of NMDA mediated responses to burst stimulation of afferent fibers in piriform cortex. J Neurosci 16:307-312.

Kapur A, Lytton WW, Ketchum KL, Haberly LB (1997) Regulation of the NMDA component of EPSPs by different components of postsynaptic GABAergic inhibition: computer simulation analysis in piriform cortex. J Neurophysiol 78:2546-2559.

Klausberger T, Magill PJ, Marton LF, Roberts JD, Cobden PM, Buzsaki G, Somogyi P (2003) Brain-state- and cell-type-specific firing of hippocampal interneurons in vivo. [comment]. Nature 421:844-848.

Klausberger T, Marton LF, Baude A, Roberts JD, Magill PJ, Somogyi P (2004) Spike timing of dendrite-targeting bistratified cells during hippocampal network oscillations in vivo. Nat Neurosci 7:41-47.

Kunec S, Hasselmo ME, Kopell N (2005) Encoding and retrieval in the CA3 region of the hippocampus: a model of theta-phase separation. J Neurophysiol 94:70-82.

Lipowsky R, Gillessen T, Alzheimer C (1996) Dendritic $\mathrm{Na}^{+}$channels amplify EPSPs in hippocampal CA1 pyramidal cells. J Neurophysiol 76:2181-2191.

Magee JC (1998) Dendritic hyperpolarization-activated currents modify the integrative properties of hippocampal CAl pyramidal neurons. J Neurosci 18:7613-7624.

Magee JC (1999) Dendritic $I_{\mathrm{h}}$ normalizes temporal summation in hippocampal CA1 neurons. Nat Neurosci 2:848.

Magistretti J, Alonso A (1999) Biophysical properties and slow voltagedependent inactivation of a sustained sodium current in entorhinal cortex layer-II principal neurons: a whole-cell and single-channel study. J Gen Physiol 114:491-509.

Markram H, Lubke J, Frotscher M, Sakmann B (1997) Regulation of synaptic efficacy by coincidence of postsynaptic APs and EPSPs. Science 275:213-215.

Miles R, Toth K, Gulyas AI, Hajos N, Freund TF (1996) Differences between somatic and dendritic inhibition in the hippocampus. Neuron 16:815-823.

Otis TS, Mody I (1992) Modulation of decay kinetics and frequency of GABAA receptor-mediated spontaneous inhibitory postsynaptic currents in hippocampal neurons. Neuroscience 49:13-32.

Pape HC (1996) Queer current and pacemaker: the hyperpolarizationactivated cation current in neurons. Annu Rev Physiol 58:299-327.

Pearce RA (1993) Physiological evidence for two distinct $\mathrm{GABA}_{\mathrm{A}}$ responses in rat hippocampus. Neuron 10:189-200.

Penttonen M, Kamondi A, Acsady L, Buzsaki G (1998) Gamma frequency oscillation in the hippocampus of the rat: intracellular analysis in vivo. Eur J Neurosci 10:718-728.

Poirazi P, Brannon T, Mel BW (2003) Pyramidal neuron as two-layer neural network. Neuron 37:989-999.
Pouille F, Scanziani M (2001) Enforcement of temporal fidelity in pyramidal cells by somatic feed-forward inhibition. Science 293:1159-1163.

Sakmann B, Edwards F, Konnerth A, Takahashi T (1989) Patch clamp techniques used for studying synaptic transmission in slices of mammalian brain. Q J Exp Physiol 74:1107-1118.

Salin PA, Prince DA (1996) Spontaneous GABAA receptor-mediated inhibitory currents in adult rat somatosensory cortex. J Neurophysiol 75:1573-1588.

Skaggs WE, McNaughton BL, Wilson MA, Barnes CA (1996) Theta phase precession in hippocampal neuronal populations and the compression of temporal sequences. Hippocampus 6:149-172.

Soltesz I, Deschenes M (1993) Low- and high-frequency membrane potential oscillations during theta activity in CA1 and CA3 pyramidal neurons of the rat hippocampus under ketamine-xylazine anesthesia. J Neurophysiol 70:97-116.

Somogyi P, Klausberger T (2005) Defined types of cortical interneurone structure space and spike timing in the hippocampus. J Physiol (Lond) 562:9-26.

Spruston N, Johnston D (1992) Perforated patch-clamp analysis of the passive membrane properties of three classes of hippocampal neurons. J Neurophysiol 67:508-529.

Stuart G (1999) Voltage-activated sodium channels amplify inhibition in neocortical pyramidal neurons. Nat Neurosci 2:144-150.

Surges R, Freiman TM, Feuerstein TJ (2004) Input resistance is voltage dependent due to activation of $I_{\mathrm{h}}$ channels in rat CA1 pyramidal cells. J Neurosci Res 76:475-480.

Tamas G, Szabadics J, Lorincz A, Somogyi P (2004) Input and frequencyspecific entrainment of postsynaptic firing by IPSPs of perisomatic or dendritic origin. Eur J Neurosci 20:2681-2690.

Tsubokawa H, Ross WN (1996) IPSPs modulate spike backpropagation and associated $\left(\mathrm{Ca}^{2+}\right)$. (i) Changes in the dendrites of hippocampal CA1 pyramidal neurons. J Neurophysiol 76:2896-2906.

van Brederode JF, Spain WJ (1995) Differences in inhibitory synaptic input between layer II-III and layer V neurons of the cat neocortex. J Neurophysiol 74:1149-1166.

Vida I, Bartos M, Jonas P (2006) Shunting inhibition improves robustness of gamma oscillations in hippocampal interneuron networks by homogenizing firing rates. Neuron 49:107-117.

Williams SR, Stuart GJ (2000) Site independence of EPSP time course is mediated by dendritic $I_{\mathrm{h}}$ in neocortical pyramidal neurons. J Neurophysiol 83:3177-3182.

Williams SR, Stuart GJ (2003) Voltage- and site-dependent control of the somatic impact of dendritic IPSPs. J Neurosci 23:7358-7367.

Ylinen A, Soltesz I, Bragin A, Penttonen M, Sik A, Buzsaki G (1995) Intracellular correlates of hippocampal theta rhythm in identified pyramidal cells, granule cells, and basket cells. Hippocampus 5:78-90. 